\title{
Thermal, spectroscopic (IR, Raman, NMR) and theoretical (DFT) studies of alkali metal complexes with pyrazinecarboxylate and 2,3-pyrazinedicarboxylate ligands
}

\author{
G. Świderski ${ }^{1} \cdot$ H. Lewandowska ${ }^{2}$ - R. Świsłocka ${ }^{1} \cdot$ S. Wojtulewski $^{3}$ • \\ L. Siergiejczyk ${ }^{3} \cdot$ A. Wilczewska ${ }^{3}$
}

Received: 28 February 2016/Accepted: 4 July 2016/Published online: 23 July 2016

(c) The Author(s) 2016. This article is published with open access at Springerlink.com

\begin{abstract}
Pyrazinecarboxylic acid and its derivatives show biological properties (inter alia antimicrobial and antifungal). In the frame of this work, the salts of 2-pyrazinecarboxylic and 2,3-pyrazinedicarboxylic acids with alkali metal cations were synthesized as well as the spectroscopic (IR, Raman, NMR), theoretical [density functional theory (DFT)] and thermogravimetric studies of obtained compounds were done. The FT-IR and FT-Raman spectra of alkali metal 2-pyrazinecarboxylates and 2,3-pyrazinedicarboxylates were recorded and analyzed in the region of $4000-400 \mathrm{~cm}^{-1}$. ${ }^{1} \mathrm{H}$ NMR and ${ }^{13} \mathrm{C}$ NMR spectra of analyzed compounds have been registered and assigned. The electronic charge distribution for the studied acids and their salts with lithium, sodium and potassium was calculated. All the calculations were done in the frame of DFT using $6-311++\mathrm{G}(\mathrm{d}, \mathrm{p})$ basis set. The thermal decomposition of the analyzed compounds was done.
\end{abstract}

Keywords Nicotinic acid derivatives .

Pyrazinecarboxylates - Spectroscopy $\cdot$ Thermal analysis · DFT studies

G. Świderski

swider30@gmail.com

1 Division of Chemistry, Bialystok University of Technology, Wiejska 45E Street, 15-351 Białystok, Poland

2 Centre for Radiobiology and Biological Dosimetry, Institute of Nuclear Chemistry and Technology, Dorodna 16, 03-195 Warsaw, Poland

3 Institut of Chemistry, University of Bialystok, Ciolkowskiego Street 1K, 15-245 Białystok, Poland

\section{Introduction}

Pyrazines, also known as p-diazines (or 1,4-diazines, Scheme 1), are compounds containing a symmetrical $\left(D_{2 \mathrm{~h}}\right)$ aromatic heterocycle $\mathrm{C}_{4} \mathrm{H}_{4} \mathrm{~N}_{2}$. In nature, there are many substituted pyrazines that carry substituents at one or more of the four ring carbon atoms. The substituents include oxygenated functional groups like alkoxy groups and acyl groups or sulfur-containing thiol or sulfide groups. Only among alkylpyrazines (containing only carbon and hydrogen substituents) ca. 70 different compounds of that type have been identified in nature $[1,2]$. The diversity of structures and roles pyrazine derivatives play in living organisms began to arouse the interest of researchers. The pyrazine derivatives have numerous prominent pharmacological effects: aspergillic acid, hydroxyaspergillic acid and other antibiotics of similar structure possess antibacterial activities [1-5]. Emimycin (3-hydroxypyrazine $N$ oxide), first isolated from Streptomyces, has been found a potent and selective inhibitor of the growth and nucleic acid synthesis in Toxoplasma gondii in human fibroblasts. Sulfonamides with pyrazine moiety are known to have high antibacterial activity [6]. Derivatives such as phenazine are well known for their antitumor, antibiotic and diuretic activities. Synthetic pyrazine derivatives exhibit a wide variety of pharmacological properties, including hypoglycemic [7-10] and diuretic [11-13] action. Pyrazinamide and its morpholino-methylene derivative act as tuberculostatic agents $[14,15]$. Structural modifications of the pyrazine ring substituents in these compounds cause modulation in their biological activity [12, 16-20]. Nicotinic and isonicotinic amidrazones are also reported in the literature as antibacterial agents [16, 21]. They also act as diuretic [22] and antimycotic [23]. Tetramethylpyrazine (also known as ligustrazine) is reported to scavenge 


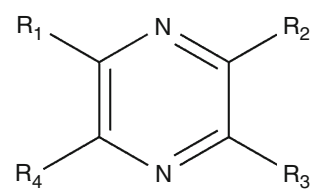

Scheme 1 General structure of diazines

superoxide anion and decrease nitric oxide production in human leukocytes [24]. For its active cardiovascular properties such as anti-platelet activity and free radical scavenging [25-27], ligustrazine has been used for the treatment of cardiovascular diseases (CVDs) in the clinic [28-30].

Pyrazines, synthesised chemically or biologically, are also used as flavoring additives. The pyrazine motif is observed in a large number of compounds that are responsible for the unique flavor and aroma of several foodstuffs and wines $[31,32]$. Orally administered substituted pyrazines are rapidly absorbed from the gastrointestinal tract and excreted [33]. It is reported in the literature that absorption of pyrazine derivatives is optimal at intestinal $\mathrm{pH}$ (ca. 6-7) $[3,5]$. The high incidence of pyrazine derivatives from the flavors of food systems and their effectiveness at very low concentrations has aroused a great interest in perfume industry [34]. Pyrazine ring is present in condensed azine dyes, for example, eurhodines, indulenes and safranines [35]. Nowadays, the pyrazine ring is a part of many polycyclic compounds of biological and/or industrial significance; examples are quinoxalines, phenazines and bio-luminescent natural products pteridines, flavins and their derivatives.

Compounds containing the quinoxaline fragment, such as Diquat, Propaquizafop and Quizalofop-ethyl, are very useful herbicides and have been used to control aquatic macrophytes [36]. While Diquat's activity consists mostly in its interaction with the photosystem I and via subsequent formation of free radicals, the two latter were shown to inhibit acetylCoA carboxylase [37, 38]. Nakamura et al. [39] synthesized sixty-six 2,3-dicyano-5-substituted pyrazines and measured their herbicidal activities against barnyard grass in pot tests to clarify the relationship between chemical structure and activity. The activity of 59 derivatives showed parabolic dependence on the hydrophobic substituent parameter at the 5-position of the pyrazine ring, indicating that the compounds should pass through a number of lipoidal-aqueous interfaces to reach a critical site for biological activity. It was found that the moiety of 2,3-dicyanopyrazine is essential for herbic ideal activity, and the 5-substituent on the pyrazine ring plays an important role in determining the potency of this activity and that para-substituted phenyl derivatives show undesirable effects on the potency of the activity at the ultimate site of herbicidal action. The results indicated that the structure of the substituted dicyanopyrazine moieties is an important function for the herbicidal activity and that the activity of these compounds is determined by the hydrophobic and steric parameters of substituents at the pyrazine ring. Similarly, Doležal et al. [40] prepared a series of substituted $N$-phenylpyrazine-2-carboxamides and diazachalcones. The most effective herbicide from the series was 6-chloro- $N$-(5-chloro-2-hydroxyphenyl)-pyrazine-2-carboxamide $\left(\mathrm{IC}_{50}=8 \mu \mathrm{mol}\right)$. The inhibitory activity of ortho-hydroxyl substituted derivatives was greater than that of their para-hydroxyl substituted isomers. An important lesson from the above mentioned studies comes from the fact that even subtle modifications of the studied pyrazine analogues have a high impact on the biological activity of a given compound. It is the time to conduct further studies aimed at rationalizing the biological activities found in order to develop more effective and clinically interesting compounds.

A renewed interest in the chemistry of pyrazine derivatives can be largely attributed to the major advances of chemotherapy, where heterocycles have been particularly prominent. Among the pyrazine-derived anticancer drugs, an epitome is a dipeptide Bortezomib, [(1R)-3methyl-1-(\{(2S)-3-phenyl-2-[(pyrazin-2-ylcarbonyl)amino] propanoyl \}amino)butyl] boronic acid, a $20 \mathrm{~S}$ proteasome complex inhibitor that acts by disrupting various cell signaling pathways, thereby leading to cell cycle arrest, apoptosis and inhibition of angiogenesis. The hallmark of bortezomib action is the inhibition of NF- $\mathrm{KB}$, thereby interfering with NF- $\mathrm{KB}$-mediated cell survival, tumor growth and angiogenesis [41] and has been applied in the treatment of cancer [42]. In the study of Kamal et al. [43], a series of oxindole derivatives of imidazo[1,5-a]pyrazines were prepared and evaluated for their anticancer activity against a panel of 52 human tumor cell lines derived from nine different cancer types: leukemia, lung, colon, CNS, melanoma, ovarian, renal, prostate and breast. Among them one compound, namely 3-(E)-1-[3-(2-Fluorophenyl)imidazo[1,5-a]pyridin-1-yl]methylidene-2-indolinone, showed significant anticancer activity with $\mathrm{GI}_{50}$ values ranging from 1.54 to $13.0 \mu \mathrm{M}$. A series of fifty-one pyrazinyl derivatives have been synthesized by Rodrigues et al. [44] and evaluated for their activity against four cancer cell lines, exhibiting good cytotoxicity $\left(\mathrm{IC}_{50}\right.$ ranging from 1.1 to $5.6 \mu \mathrm{g} \mathrm{mL}^{-1}$ ). Structure-activity relationship (SAR) analysis indicated that the hydroxyl group located in ortho position is critical for the biological activity of these compounds. The presence of hydroxyl groups on benzene ring plays an important role in the anticancer activity of this series, feature especially observed in disubstituted derivatives. The mentioned instances on new pyrazine-derived drug development give a clear notion, how important for the successful research is understanding of the SAR analysis approach. 
In the frame of our previous works, we studied the effect of over 40 metal cations on the electronic system, physicochemical and biological properties of different ligands-derivatives of benzoic [45-49] acids. The complexations of aromatic carboxylic acids by metal cations change the electronic charge distribution within the aromatic ring and the carboxylate anion. So far, our studies showed that the effect of metal cation on the electronic structure of pyridine ring of pyridinecarboxylic acids depends on the position of nitrogen atom within the carboxylic acid structure. In this work, the effect of alkali metal cations on the electronic structure of derivatives of pyrazine was studied. We have studied the salts of pyrazine 2-carboxylic acid (2PCA) and pyrazine 2,3-dicarboxylic acid (2,3PDCA) alkali metal salts. A range of complementary methods were used to determine the effect of alkali metals on the changes in the distribution of electronic charge in the pyrazine ring of the analyzed acids. As part of the work, we also investigated the impact of alkali metals on the (thermal stabilization) of the 2-pyrazinecarboxylic and 2,3-pyrazinedicarboxylic acids. These studies also allowed, along with the elementary analysis, to determine the degree of hydration of the tested salts.

\section{Experimental and theoretical calculations}

\section{Sample preparation}

The alkali metal salt of 2-pyrazinecarboxylic (2PCA) and 2,3pyrazinedicarboxylic acids (2,3PDCA) was prepared by dissolving appropriate weighed amount of particular acids in hot aqueous solution of alkali metal hydroxides in a stoichiometric ratio ligand/metal-1:1 for 2-pyrazinecarboxylates and 1:2 for 2,3-pyrazinedicarboxylates. To $1 \mathrm{mmol}$ of 2-PCA $10 \mathrm{~cm}^{3}$ of $0.1 \mathrm{~mol} / \mathrm{L}$ alkali metal hydroxide solution in water was added. The solutions were than heated in a shaker to ca $80^{\circ} \mathrm{C}$ for $1 \mathrm{~h}$. Then, the solutions were left at RT for $24 \mathrm{~h}$. Next, they were evaporated and dried at $50^{\circ} \mathrm{C}$ for $24 \mathrm{~h}$. In order to obtain alkali metal salts with 2,3-pyrazinedicarboxylic acid, $0.1 \mathrm{mmol}$ of acid was diluted in $20 \mathrm{~mL}$ of corresponding metal hydroxide $\left(0.1 \mathrm{~mol} \mathrm{~L}^{-1}\right)$. Salts of 2,3 pyrazinedicarboxylate acid were prepared analogically.

\section{Measurement and calculation}

The FT-IR spectra were recorded with an Alfa (Bruker) spectrometer within the range of $400-4000 \mathrm{~cm}^{-1}$. Samples in the solid state were measured in $\mathrm{KBr}$ matrix pellets and ATR technique. FT-Raman spectra of solid samples were recorded in the range of $400-4000 \mathrm{~cm}^{-1}$ with a MultiRam (Bruker) spectrometer. The resolution of the spectrometer was $1 \mathrm{~cm}^{-1}$. The ${ }^{1} \mathrm{H}$ and ${ }^{13} \mathrm{C}$ NMR spectra of $\mathrm{D}_{2} \mathrm{O}$ solution of studied compounds were recorded with a Bruker Avance II $400 \mathrm{MHz}$ unit at room temperature. TMS was used as an internal reference. To calculate optimized geometrical structures of 2-pyrazinecarboxylic and 2,3-pyrazinecarboxylic acid and lithium, sodium and potassium salts, quantum-mechanical method was used: density functional (DFT) hybrid method B3LYP with non-local correlation provided by Lee-Young-Parr expression. All calculations were carried out with functional base $6-311++G(d, p)$. Calculations were performed using the Gaussian09 package [50]. Experimental spectra were interpreted in terms of calculated at DFT method in B3LYP/6-311++G(d,p) level and literature data [51]. Theoretical wavenumbers were scaled according to the formula: $v_{\text {scaled }}=0.98 \cdot v_{\text {calculated }}$ for B3LYP/6-311++G(d,p) level method [52] Chemical shifts $\left(\delta_{\mathrm{i}}\right)$ were calculated by subtracting the appropriate isotopic part of the shielding tensor $\left(\sigma_{\mathrm{i}}\right)$ from that of TMS $\left(\sigma_{\mathrm{TMS}}\right)$ : $\delta_{\mathrm{i}}=\sigma_{\mathrm{TMS}}-\sigma_{\mathrm{i}}(\mathrm{ppm})$. The isotropic shielding constants for TMS calculated using the DFT method at the same level of theory were equal to $31.8201 \mathrm{ppm}$ and $182.4485 \mathrm{ppm}$ for the ${ }^{1} \mathrm{H}$ nuclei and the ${ }^{13} \mathrm{C}$ nuclei, respectively. The electronic charge distribution was calculated with natural bond orbital (NBO) [53] at B3LYP/6-311++G(d,p) level of theory. The HOMA [54] and Bird $I_{6}$ [55] aromaticity indices were calculated for theoretical structures. The products of dehydration and decomposition processes were determined from the TG curves. Thermogravimetric analysis (TG) was performed on a Mettler Toledo Star TGA/DSC1 unit. Argon was used as a purge gas $\left(20 \mathrm{~mL} \mathrm{~min}^{-1}\right)$. Samples between 2 and $4 \mathrm{mg}$ were placed in aluminum pans and heated from 50 to $850{ }^{\circ} \mathrm{C}$ with a heating rate of $10{ }^{\circ} \mathrm{C} \mathrm{min}^{-1}$.

\section{Results and discussion}

\section{Thermal study and elemental analysis}

Alkali metal salts of the pyrazino 2-carboxylic acid 2,3pyrazine dicarboxylic acids were dried for $24 \mathrm{~h}$ at $50{ }^{\circ} \mathrm{C}$. The degree of hydration of the salt defined on the basis of thermogravimetric and elemental analysis was limited. Sodium, potassium and rubidium 2-pyrazinecarboxylates and sodium 2,3-pyrazinecarboxylate were anhydrous. For other salts, the degree of hydration ranged from 0.5 to 1.5 $\mathrm{H}_{2} \mathrm{O}$ per molecule (Tables 1, 2; Fig. 1). Dehydration of the salts studied takes place in a single step (for all the hydrated salts). The press of thermal decomposition of both ligands is a single step press occurring at similar temperatures. 2,3-Pyrazinecarboxylic acid decomposes at about $210{ }^{\circ} \mathrm{C}$, and 2-pyrazinecarboxylic acid at about $230{ }^{\circ} \mathrm{C}$. Thermal decomposition of the salts studied takes place in several stages. The products of the first stage of the lithium salts decomposition are lithium carbonates and organic 
Table 1 Elemental analysis and thermogravimetric analysis for lithium, sodium, potassium, rubidium and cesium 2-pyrazinecarboxylates

\begin{tabular}{|c|c|c|c|c|c|c|c|c|c|c|}
\hline \multirow[t]{3}{*}{ Compound $^{\mathrm{a}}$} & \multicolumn{6}{|c|}{ Elemental analysis } & \multirow[t]{3}{*}{ Range of decomposition } & \multicolumn{2}{|c|}{ Mass loss $/ \%$} & \multirow[t]{3}{*}{ Product decomposition } \\
\hline & \multicolumn{2}{|c|}{ Content $\mathrm{C} / \%$} & \multicolumn{2}{|c|}{ Content $\mathrm{H} / \%$} & \multicolumn{2}{|c|}{ Content N/\% } & & \multirow[t]{2}{*}{ Calc. } & \multirow[t]{2}{*}{ Exp. } & \\
\hline & Exp. & Calc. & Exp. & Calc. & Exp. & Calc. & & & & \\
\hline \multirow[t]{3}{*}{$\mathrm{Li}_{2} \mathrm{~L} \cdot 0.75 \mathrm{H}_{2} \mathrm{O}$} & 41.1 & 41.79 & 3.13 & 2.90 & 18.52 & 19.51 & $80-110$ & 95.91 & 96.70 & $\mathrm{Li}_{2} \mathrm{~L}$ \\
\hline & & & & & & & $350-450$ & 59.17 & 57.50 & $\mathrm{Li}_{2} \mathrm{CO}_{3}+\mathrm{C}_{\text {org }}$ \\
\hline & & & & & & & $550-850$ & 25.75 & 22.50 & $\mathrm{Li}_{2} \mathrm{CO}_{3}$ \\
\hline \multirow[t]{2}{*}{$\mathrm{Na}_{2} \mathrm{~L}$} & 41.13 & 41.07 & 1.95 & 2.05 & 18.89 & 19.16 & $230-330$ & 63.28 & 63.50 & $\mathrm{Na}_{2} \mathrm{CO}_{3}+\mathrm{C}_{\text {org }}$ \\
\hline & & & & & & & $850<$ & 36.27 & - & $\mathrm{Na}_{2} \mathrm{CO}_{3}$ \\
\hline \multirow[t]{2}{*}{$\mathrm{K}_{2} \mathrm{~L}$} & 36.48 & 36.99 & 1.64 & 1.85 & 16.28 & 17.26 & $380-450$ & 66.64 & 66.50 & $\mathrm{~K}_{2} \mathrm{CO}_{3}+\mathrm{C}_{\text {org }}$ \\
\hline & & & & & & & $450-850$ & 42.60 & 44.00 & $\mathrm{~K}_{2} \mathrm{CO}_{3}$ \\
\hline \multirow[t]{2}{*}{$\mathrm{Rb}_{2} \mathrm{~L}$} & 28.10 & 28.77 & 1.25 & 1.44 & 12.26 & 13.42 & $440-490$ & 73.61 & 72.50 & $\mathrm{Rb}_{2} \mathrm{CO}_{3}+\mathrm{C}_{\text {org }}$ \\
\hline & & & & & & & $490-850$ & 55.36 & 55.50 & $\mathrm{Rb}_{2} \mathrm{CO}_{3}$ \\
\hline \multirow[t]{2}{*}{$\mathrm{Cs}_{2} \mathrm{~L} \cdot 0.5 \mathrm{H}_{2} \mathrm{O}$} & 23.26 & 22.63 & 1.40 & 1.51 & 10.62 & 10.56 & $220-250$ & 96.61 & 96.65 & $\mathrm{Cs}_{2} \mathrm{~L}$ \\
\hline & & & & & & & $330-430$ & 78.25 & 78.50 & $\mathrm{Cs}_{2} \mathrm{CO}_{3}+\mathrm{C}_{\mathrm{org}}$ \\
\hline
\end{tabular}

${ }^{\mathrm{a}} \mathrm{L}=2 \mathrm{PCA}$ (ligand $=2$-pyrazinecarboxylic acid)

Table 2 Elemental analysis and thermogravimetric analysis for lithium, sodium, potassium, rubidium and cesium 2,3-pyrazinedicarboxylates

\begin{tabular}{|c|c|c|c|c|c|c|c|c|c|c|}
\hline \multirow[t]{3}{*}{ Compound $^{\mathrm{a}}$} & \multicolumn{6}{|c|}{ Elemental analysis } & \multirow{3}{*}{$\begin{array}{l}\text { Range of } \\
\text { decomposition }\end{array}$} & \multicolumn{2}{|c|}{ Mass loss $/ \%$} & \multirow{3}{*}{$\begin{array}{l}\text { Product } \\
\text { decomposition }\end{array}$} \\
\hline & \multicolumn{2}{|c|}{ Content $\mathrm{C} / \%$} & \multicolumn{2}{|c|}{ Content $\mathrm{H} / \%$} & \multicolumn{2}{|c|}{ Content N/\% } & & Calc. & Exp. & \\
\hline & Exp. & Calc. & Exp. & Calc. & Exp. & Calc. & & & & \\
\hline \multirow[t]{3}{*}{$\mathrm{Li}_{2} \mathrm{~L} \cdot 0.75 \mathrm{H}_{2} \mathrm{O}$} & 39.59 & 40.00 & 1.18 & 1.11 & 15.07 & 15.56 & $220-270$ & 95.24 & 94.80 & $\mathrm{Li}_{2} \mathrm{~L}$ \\
\hline & & & & & & & $350-450$ & 74.38 & 74.50 & $\mathrm{Li}_{2} \mathrm{CO}_{3}+\mathrm{C}_{\text {org }}$ \\
\hline & & & & & & & $450-850$ & 39.99 & 35.00 & $\mathrm{Li}_{2} \mathrm{CO}_{3}$ \\
\hline $\mathrm{Na}_{2} \mathrm{~L}$ & 33.81 & 33.95 & 0.96 & 0.94 & 12.66 & 13.20 & $410-460$ & 78.26 & 81.00 & $\mathrm{Na}_{2} \mathrm{CO}_{3}+\mathrm{C}_{\text {org }}$ \\
\hline \multirow[t]{3}{*}{$\mathrm{K}_{2} \mathrm{~L} \cdot 0.5 \mathrm{H}_{2} \mathrm{O}$} & 27.40 & 28.42 & 0.97 & 1.18 & 9.72 & 10.05 & $50-100$ & 96.58 & 96.85 & $\mathrm{~K}_{2} \mathrm{~L}$ \\
\hline & & & & & & & $350-490$ & 81.13 & 80.00 & $\mathrm{~K}_{2} \mathrm{CO}_{3}+\mathrm{C}_{\text {org }}$ \\
\hline & & & & & & & $490-800$ & 54.56 & 55.00 & $\mathrm{~K}_{2} \mathrm{CO}_{3}$ \\
\hline \multirow[t]{3}{*}{$\mathrm{Rb}_{2} \mathrm{~L} \cdot \mathrm{H}_{2} \mathrm{O}$} & 19.33 & 20.27 & 1.11 & 1.13 & 7.46 & 7.88 & $90-120$ & 94.93 & 94.70 & $\mathrm{Rb}_{2} \mathrm{~L}$ \\
\hline & & & & & & & $350-400$ & 86.32 & 85.00 & $\mathrm{Rb}_{2} \mathrm{CO}_{3}+\mathrm{C}_{\mathrm{org}}$ \\
\hline & & & & & & & $400-700$ & 64.63 & - & $\mathrm{Rb}_{2} \mathrm{CO}_{3}$ \\
\hline \multirow[t]{3}{*}{$\mathrm{Cs}_{2} \mathrm{~L} \cdot 1.5 \mathrm{H}_{2} \mathrm{O}$} & 15.44 & 15.68 & 0.93 & 1.09 & 5.18 & 7.61 & $110-180$ & 94.12 & 94.40 & $\mathrm{Cs}_{2} \mathrm{~L}$ \\
\hline & & & & & & & $340-400$ & 87.45 & 87.00 & $\mathrm{Cs}_{2} \mathrm{CO}_{3}+\mathrm{C}_{\text {org }}$ \\
\hline & & & & & & & $400-700$ & 64.63 & - & $\mathrm{Cs}_{2} \mathrm{CO}_{3}$ \\
\hline
\end{tabular}

${ }^{\mathrm{a}} \mathrm{L}=2,3 \mathrm{PDCA}$ (ligand $=2,3$-pyrazinedicarboxylic acid)

carbon residues formed during the decomposition of the aromatic ring (Tables 1, 2; Figs. 1, 2). For both ligands, press takes place at the same temperature of $350-450{ }^{\circ} \mathrm{C}$. Further heating of lithium salts leads to combustion of organic carbon residue. The final product of this decomposition step is lithium carbonate (at a temperature of about $850{ }^{\circ} \mathrm{C}$ for 2-pyrazinecarboxylate (Fig. 1) and $750{ }^{\circ} \mathrm{C}$ for 2,3-pyrazinedicarboxylate (Fig. 2). The sodium 2-pyrazinecarboxylic probably undergoes thermal decomposition into sodium carbonate at a temperature higher than $850{ }^{\circ} \mathrm{C}$ (outside the test temperature range). Intermediate product of this decomposition is a mixture of sodium carbonate and residual organic carbon from the decomposition of the pyrazine ring (this product is formed in the temperature range of $500-600{ }^{\circ} \mathrm{C}$ ). Thermal decomposition of sodium 2,3-pyrazinedicarboxylate yields a mixture of sodium carbonate and organic carbon, which decompose to sodium carbonate at a temperature above $850{ }^{\circ} \mathrm{C}$. The final decomposition product of potassium 2,3-pyrazinedicarboxylate is potassium carbonate (formed at a temperature above $800{ }^{\circ} \mathrm{C}$ ). The intermediate product is a mixture of potassium carbonate and residual organic carbon from the decomposition of the pyrazine ring (this product is formed in the temperature range of $350-490{ }^{\circ} \mathrm{C}$ ). 

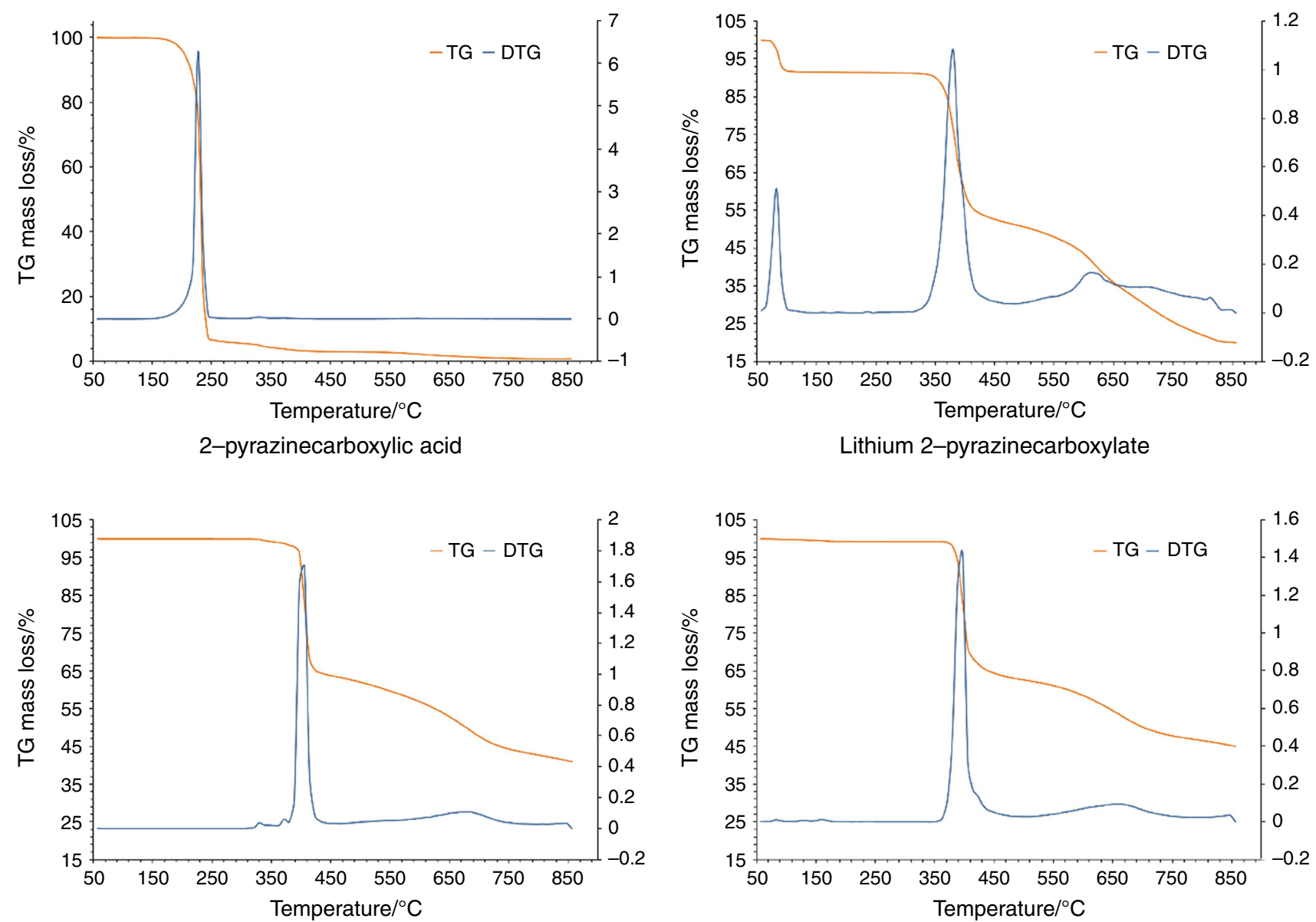

Sodium 2-pyrazinecarboxylate

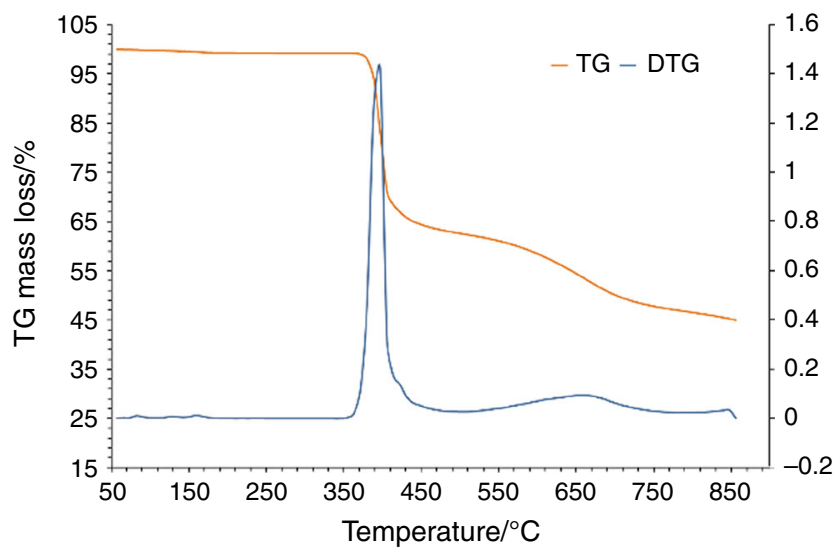

Potassium 2-pyrazinecarboxylate

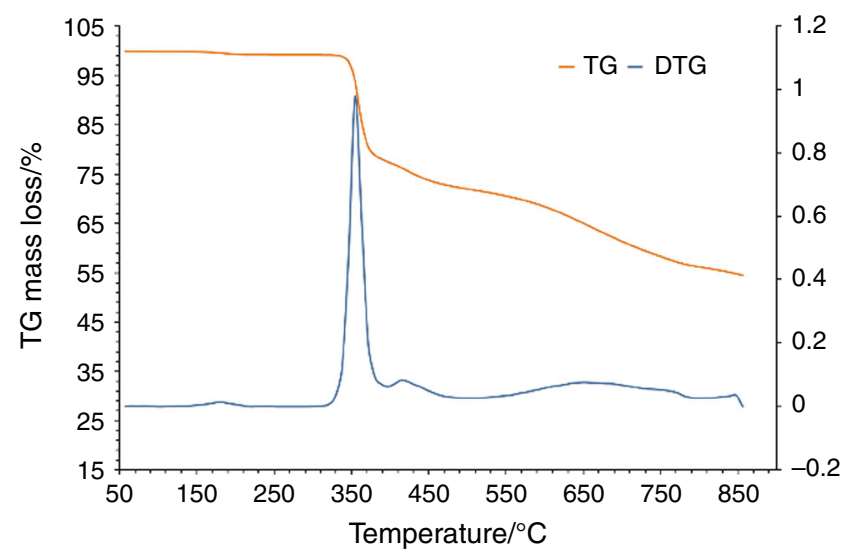

Rubidium 2-pyrazinecarboxylate

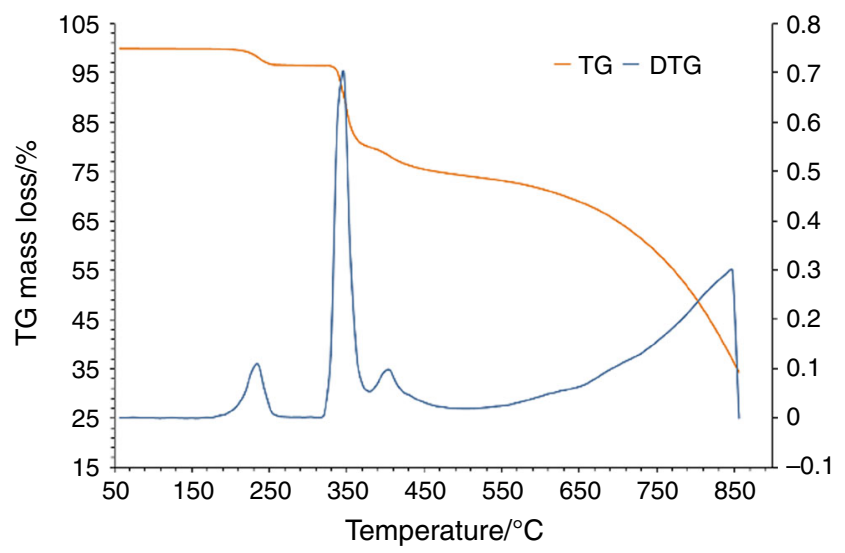

Caesium 2-pyrazinecarboxylate

Fig. 1 Curves of thermal decomposition (TG and DTG curves) of alkali metal salts with 2-pyrazinecarboxylic acid (2PCA) - left diagrams and 2,3-pyrazinedicarboxylic acid (2,3PDCA)—right diagrams

In the case of potassium 2-pyrazinecarboxylate, the final product of degradation is potassium carbonate (at a temperature of $850{ }^{\circ} \mathrm{C}$ ). An intermediate product is a mixture of potassium carbonate and organic carbon. The process of thermal decomposition of 2-pyrazinecarboxylate rubidium occurs in two stages. In the first stage taking place at a temperature of from 340 to $390{ }^{\circ} \mathrm{C}$, a mixture of rubidium carbonate and organic carbon is formed (Fig. 1), and the second step yields rubidium carbonate (at a temperature of from 390 to $850{ }^{\circ} \mathrm{C}$ ). The intermediate product of 


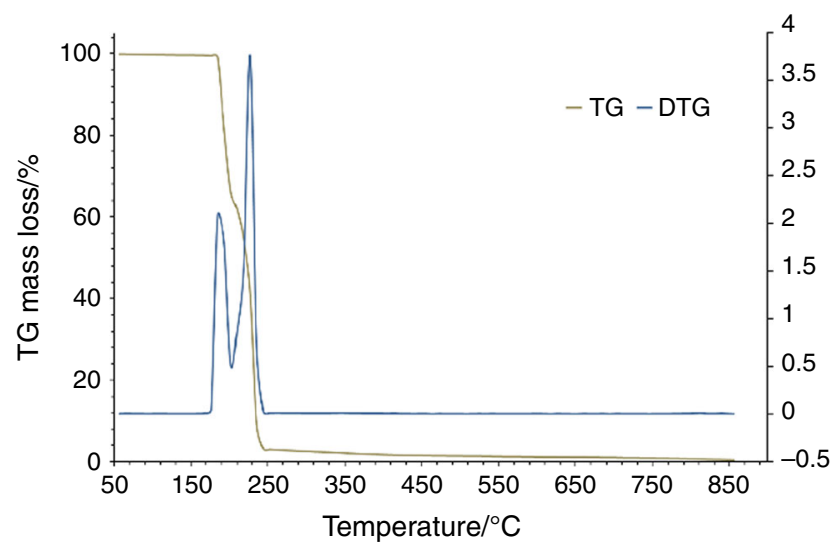

2,3-pyrazinedicarboxylic acid

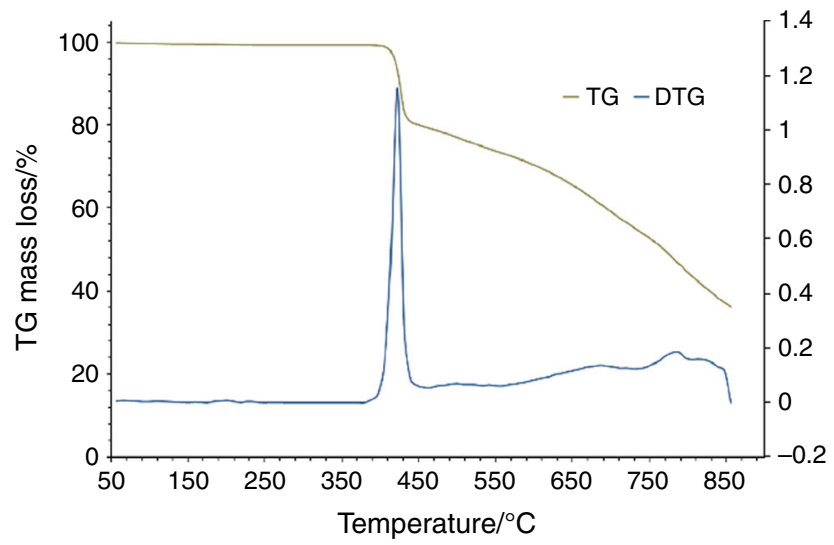

Sodium 2,3-pyrazinedicarboxylate

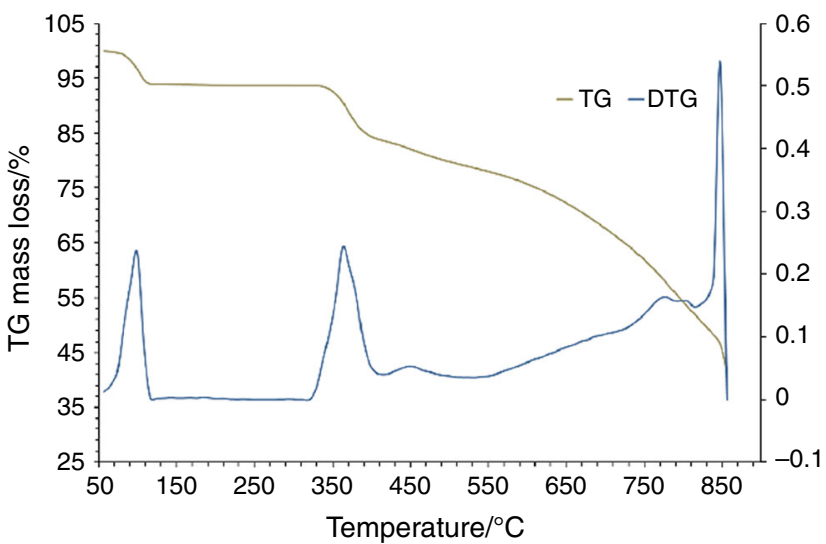

Rubidium 2,3-pyrazinedicarboxylate

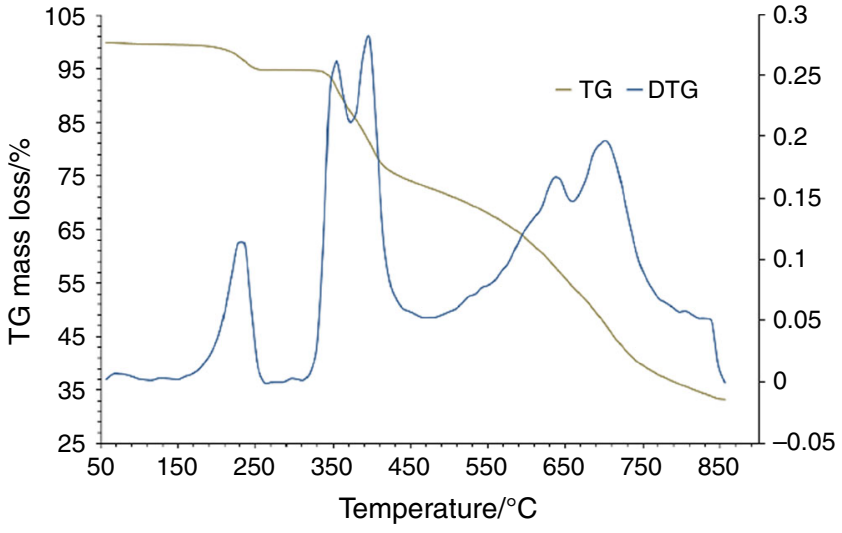

Lithium 2,3-pyrazinedicarboxlate

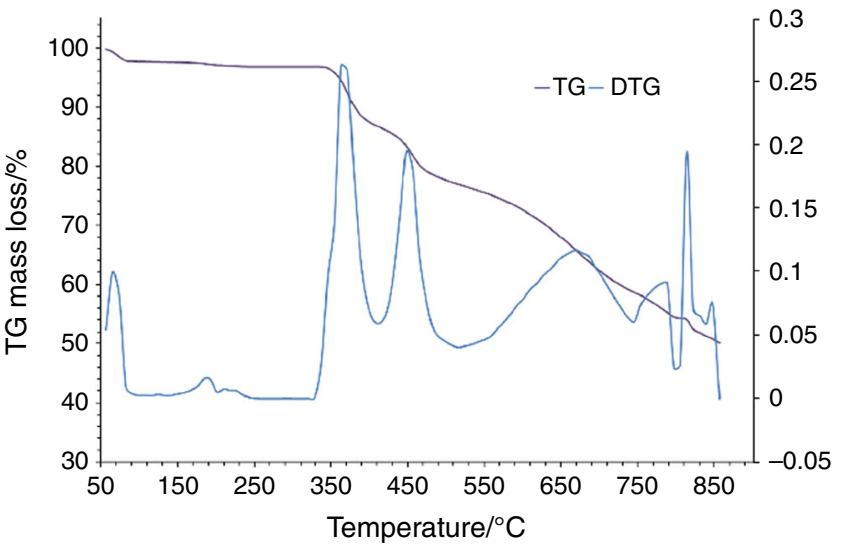

Potassium 2,3-pyrazinedicarboxylate

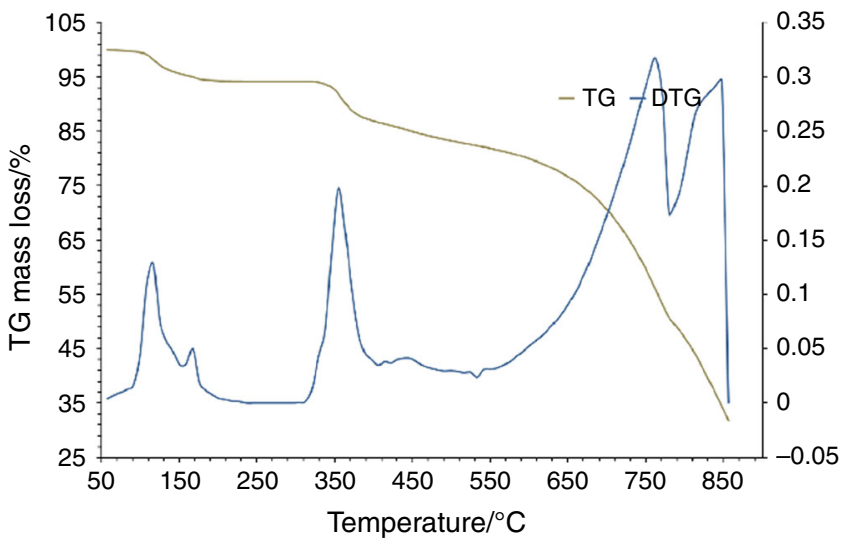

Caesium 2,3-pyrazinedicarboxylate

Fig. 2 Curves of thermal decomposition (TG and DTG curves) of alkali metal salts with 2,3-pyrazinedicarboxylic acid (2,3PDCA)

decomposition of rubidium 2,3-pyrazinedicarboxylate is a mixture of rubidium carbonate and residual organic carbon from the decomposition of the pyrazine ring (this product is formed in the temperature range of $\left.350-400{ }^{\circ} \mathrm{C}\right)$. Further heating leads to unidentified products (Fig. 2).

The decomposition process of the cesium 2-pyrazinecarboxylate gives a mixture of cesium carbonate and carbon, which decomposes in the next step of heating, yielding probably the cesium oxide, $\mathrm{Cs}_{2} \mathrm{O}$.

Also, heating of cesium salt of 2,3-pyrazine dicarboxylic acid also gave a mixture of cesium carbonate and organic carbon; nevertheless, further heating leads to the formation of other products that could not be identified (unknown stable breakdown products - probably the cesium oxide, $\mathrm{Cs}_{2} \mathrm{O}$ ). 
Comparing the curves of the thermal decomposition of the alkali metal salt of either acid, we observed that salts of 2-pyrazinecarboxylic acid decomposed at a slightly higher temperature than the salts of 2,3-pyrazinedicarboxylic acid. For all of the alkali metal salts of both ligands, thermal decomposition occurred yielding an intermediate product that was a mixture of alkali metal carbonate and organic carbon residues formed during decomposition of an aromatic acid. It was also observed that in the case of cesium salt, the carbonates formed were unstable and underwent further degradation at temperatures above $430{ }^{\circ} \mathrm{C}(2 \mathrm{PCA}$ acid salt) and above $700{ }^{\circ} \mathrm{C}$ (salt of 2,3PDCA).

\section{IR and Raman study}

Table 3 shows the wavenumbers and intensities of the bands present in IR spectra registered in the $\mathrm{KBr}$ matrix by ATR technique and as well those theoretically calculated by DFT (B3LYP-6-311++G**) and Raman spectra of 2-pyrazinecarboxylate and its salts with alkali metals. Table 4, in turn, shows the registered and calculated wavenumbers and intensities of the IR bands as well as the Raman spectra of 2,3-pyrazinedicarboxylate and alkali metal salts thereof. The experimental spectra were interpreted based on theoretical calculations and data presented in the literature [51]. The normal ring vibrations of aromatic acids and salts were assigned according to the Varsányi numbering [56]. Figure 3 shows the experimental spectrum recorded in $\mathrm{KBr}$ matrix and the Raman spectrum of 2-pyrazinecarboxylic acid and the chosen salt (of sodium). In the spectra of the salts, the characteristic vibrational bands of the carboxylate anion can be observed. These include asymmetric stretching vibration band of the carboxylate anion $\mathrm{v}_{\mathrm{as}} \mathrm{COO}^{-}$and symmetric stretching vibration band $\mathrm{v}_{\mathrm{s}} \mathrm{COO}^{-}$. For the salts of 2-pyrazinecarboxylate upon the coordination of the carboxyl group the alkali metal cation, there appears a single band of $v_{\text {as }} \mathrm{COO}^{-}$vibration, present in the studied salts in the wavenumber range: $1619-1615 \mathrm{~cm}^{-1} \quad\left(\mathrm{IR}_{\mathrm{KBr}}\right)$, $1631-1613 \mathrm{~cm}^{-1}\left(\mathrm{IR}_{\mathrm{ATR}}\right)$ and $1646-1617 \mathrm{~cm}^{-1}$ (Raman) and a single band of $\mathrm{v}_{\mathrm{s}} \mathrm{COO}^{-}$vibration present in the range of $1389-1381 \mathrm{~cm}^{-1}\left(\mathrm{IR}_{\mathrm{KBr}}\right), 1385-1369 \mathrm{~cm}^{-1}\left(\mathrm{IR}_{\mathrm{ATR}}\right)$ and $1393-1382 \mathrm{~cm}^{-1}$ (Raman). There was also observed some single asymmetric and symmetric bending vibrations in the plane of the carboxylate anion $\beta_{\mathrm{as}} \mathrm{COO}^{-}$and $\beta_{\mathrm{s}} \mathrm{COO}^{-}$ respectively at wavenumbers: $538-516 \mathrm{~cm}^{-1}\left(\mathrm{IR}_{\mathrm{KBr}}\right)$, $548-517 \mathrm{~cm}^{-1}\left(\mathrm{IR}_{\mathrm{ATR}}\right)$ and $547-512 \mathrm{~cm}^{-1}$ (Raman) and $855-848 \mathrm{~cm}^{-1} \quad\left(\mathrm{IR}_{\mathrm{KBr}}\right), \quad 854-840 \mathrm{~cm}^{-1} \quad\left(\mathrm{IR}_{\mathrm{ATR}}\right)$ and $859-842 \mathrm{~cm}^{-1}$. In the spectra of alkali metal 2-pyrazinecarboxylates, there were also observed the symmetrical out-ofplane bending vibrations of the carboxylate anion $\gamma_{s} \mathrm{COO}^{-}$in the ranges of: $807-795 \mathrm{~cm}^{-1}\left(\mathrm{IR}_{\mathrm{KBr}}\right), 797-786 \mathrm{~cm}^{-1}\left(\mathrm{IR}_{\mathrm{ATR}}\right)$ and $799-786 \mathrm{~cm}^{-1}$ (Raman). The coordination of the alkali metal atom by the carboxyl group induces the formation of the carboxylate anion and the change in electron charge distribution within that group. Along with the change in an alkali metal atom in the salt (in the series $\mathrm{Li}-\mathrm{Na}-\mathrm{K}-\mathrm{Rb}-\mathrm{Cs}$ ) the charge distribution and the degree of metal-ligand binding as manifested by changes in wavenumbers bands derived from the carboxylate anion vibration $\mathrm{v}_{\mathrm{s}} \mathrm{COO}^{-}$and $\mathrm{v}_{\mathrm{as}} \mathrm{COO}^{-}$. Change in the ionic character of bond is associated with the increase or decrease in the disparity of $\mathrm{v}_{\mathrm{s}} \mathrm{COO}^{-}$and $\mathrm{v}_{\mathrm{as}} \mathrm{COO}^{-}$ band wavenumbers in the spectra of salt in the test series (parameter $\Delta v=v_{\mathrm{as}} \mathrm{COO}-\mathrm{v}_{\mathrm{s}} \mathrm{COO}^{-}$).

We observed a decrease in the $\Delta v$ the IR spectra are $\mathrm{IR}_{\mathrm{ATR}}, \mathrm{IR}_{\mathrm{KBr}}$, Raman spectra in the studied salts in the series $\mathrm{Li}-\mathrm{Na}-\mathrm{K}-\mathrm{Rb}-\mathrm{Cs}$. In the case of the $\mathrm{IR}_{\mathrm{KBr}}$ spectra, these changes were irregular in the studied series of metal salts. A similar effect was observed earlier in the case of alkali metal salts of other ligands, including 2-pyridinecarboxylic acid [57, 58]. We also observed the dependencies between some parameters of metals (including metal ion potential) and the values of the wavenumbers of carboxylate anion vibrations in the salts of the given metals with different ligands.

In the studied 2,3-pyrazinedicarboxylate alkali metal salts, the ratio of ligand to metal is 1:2. Both carboxyl groups of the ligand are substituted with an alkali metal. The spectra of these salts comprise each the two bands derived from symmetric stretching vibration $v_{\mathrm{s}} \mathrm{COO}^{-}$carboxylate anion and two bands derived from asymmetric stretching vibration carboxylate anion $\mathrm{v}_{\mathrm{as}} \mathrm{COO}^{-}$(Fig. 4; Table 4). $\mathrm{v}_{\mathrm{as}} \mathrm{COO}^{-}$ vibration bands appear at wavenumbers: $1641-1613$ and $1600-1588 \mathrm{~cm}^{-1}\left(\mathrm{IR}_{\mathrm{KBr}}\right), 1641-1612$ and $1595-1585 \mathrm{~cm}^{-1}$ $\left(\mathrm{IR}_{\mathrm{ATR}}\right)$ and 1631-1604 and 1604-1586 $\mathrm{cm}^{-1}$ (Raman). $v_{\mathrm{S}} \mathrm{COO}^{-}$vibration bands appear at wavenumbers: $1398-1388$ and $1361-1351 \mathrm{~cm}^{-1}\left(\mathrm{IR}_{\mathrm{KBr}}\right), 1399-1389$ and $1361-1351 \mathrm{~cm}^{-1} \quad\left(\mathrm{IR}_{\mathrm{ATR}}\right)$ and 1401-1388 and $1366-1357 \mathrm{~cm}^{-1}$ (Raman). In the spectra of 2,3-pyrazinodicarboksylates of alkali metals, one can also observe two strands coming from asymmetric and symmetric in the plane bending vibrations of the carboxylate anion $\beta_{\mathrm{as}} \mathrm{COO}^{-}$and $\beta_{\mathrm{s}} \mathrm{COO}^{-}$and two symmetrical out-of-plane bending vibration bands of the carboxylate anion $\gamma_{\mathrm{s}} \mathrm{COO}^{-}$(Table 4). The wavenumbers of bands coming from the carboxylate anion vibrations change irregularly in the studied series of metal salts. The observed changes in the parameter $\Delta v=v_{\text {as- }}$ $\mathrm{COO}-v_{\mathrm{s}} \mathrm{COO}^{-}$for a series of 2,3-pyrazinedicarboxylates ( $\mathrm{Li}-\mathrm{Na}-\mathrm{K}-\mathrm{Rb}-\mathrm{Cs})$ are also irregular.

Analyzing the values of wavenumbers and intensities of the bands derived from the vibration of the aromatic ring in the salts of 2PCA and 2,3PDCA acids, one can find a number of characteristic differences as compared to the spectra of ligands. Some of the bands present in the spectra of acids disappear for salts. Wavenumbers and intensities of most of the bands decrease in the salts in relation to the ligand. The disappearance of the bands, decrease in the 


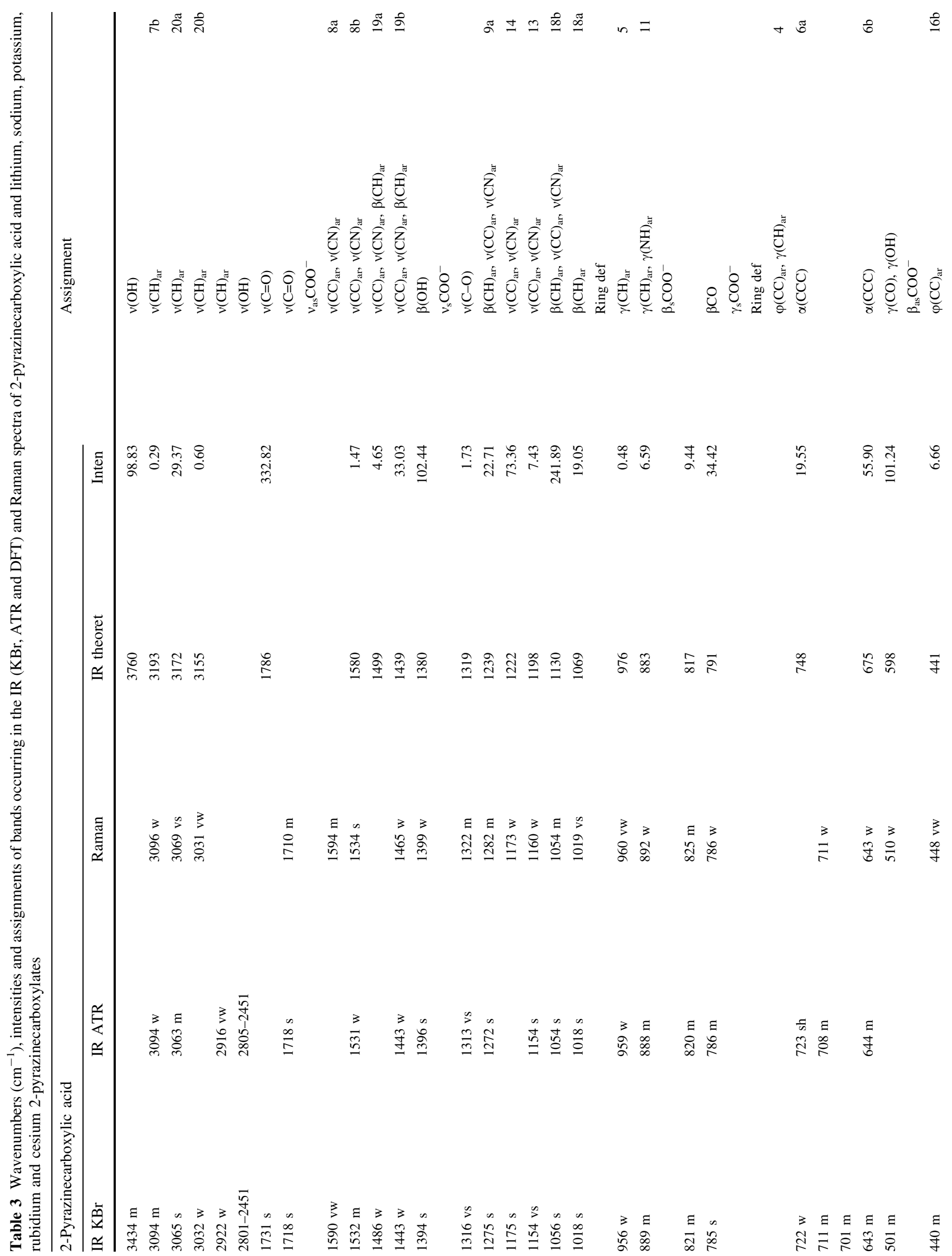




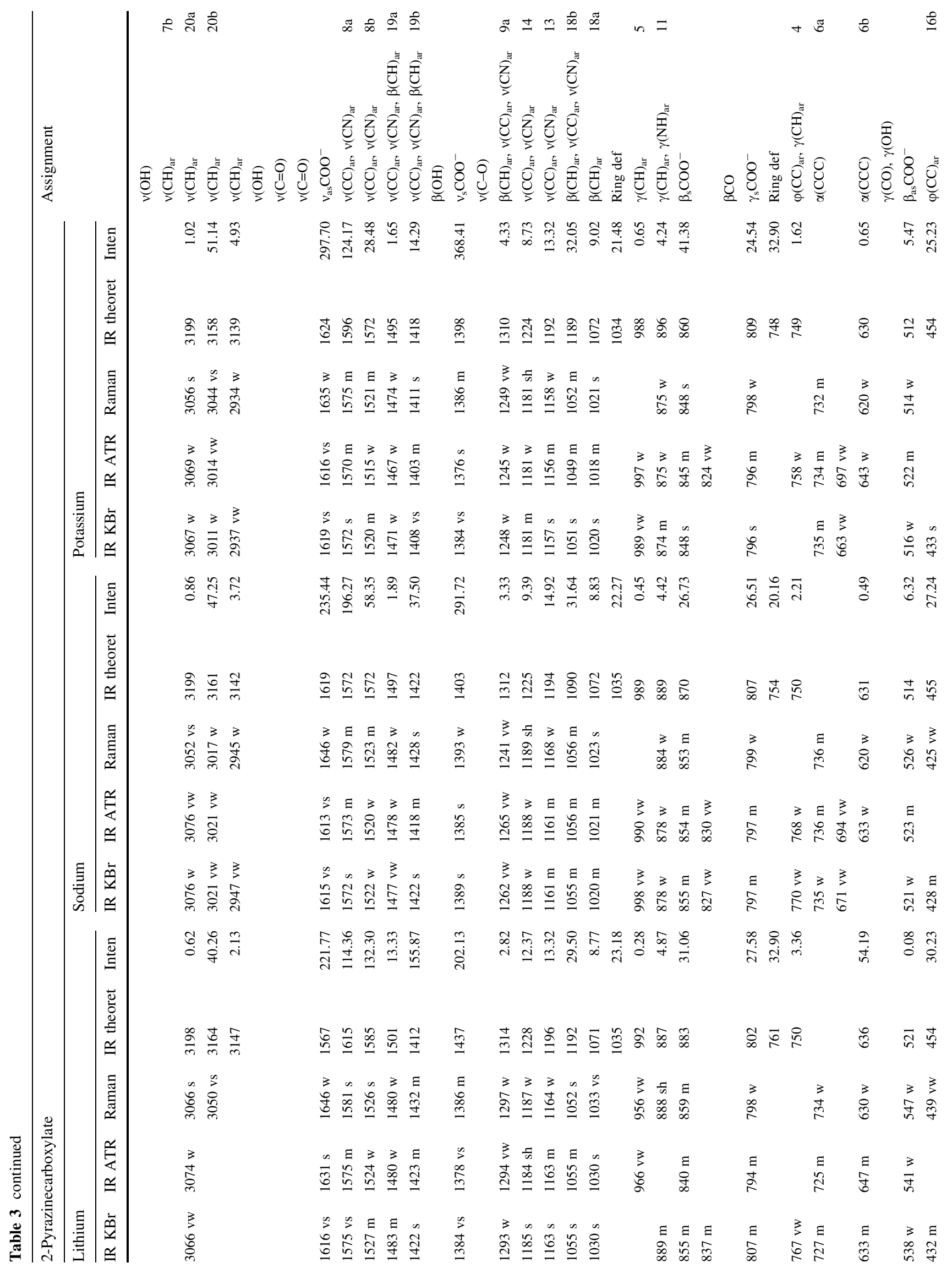




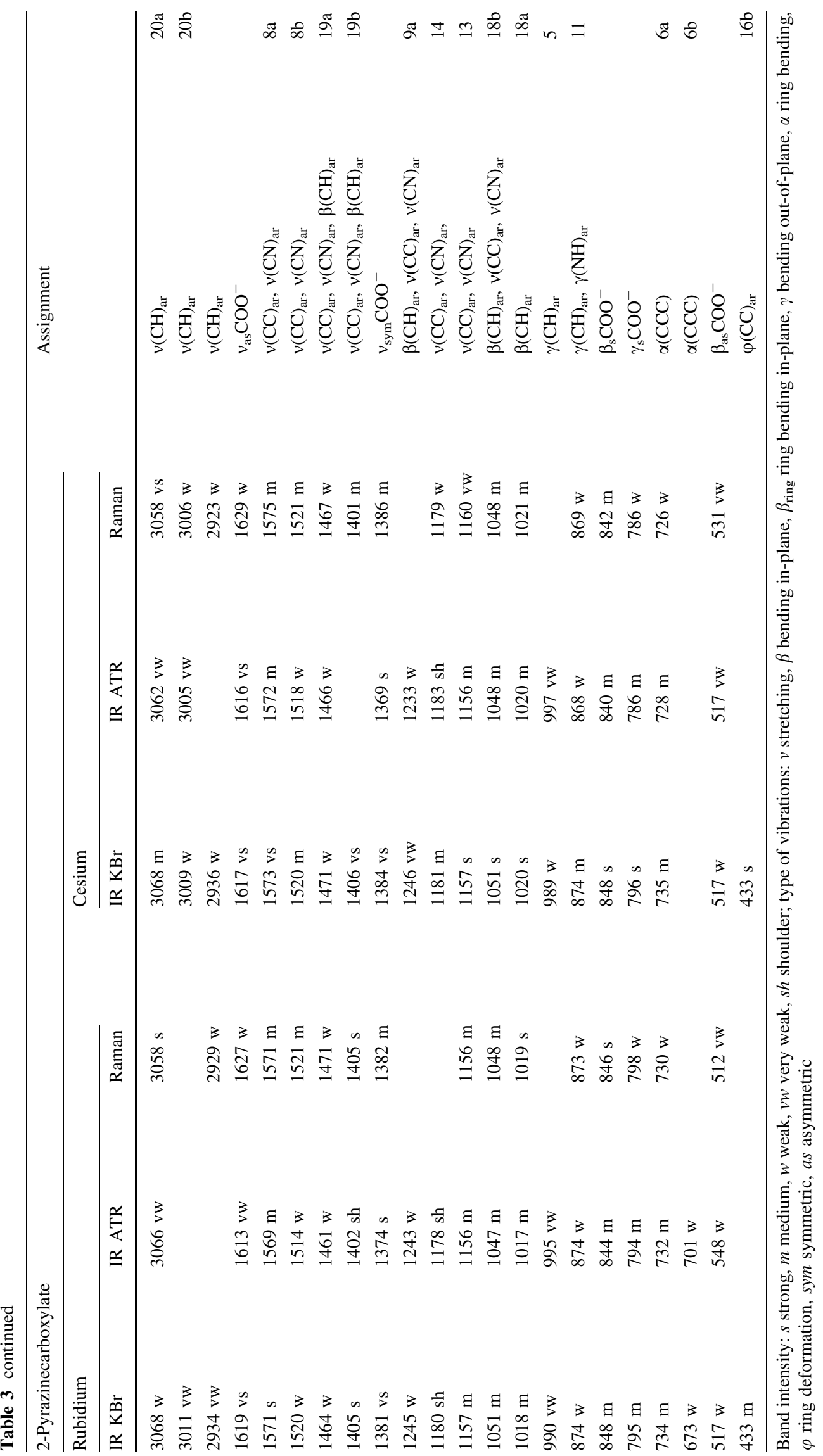




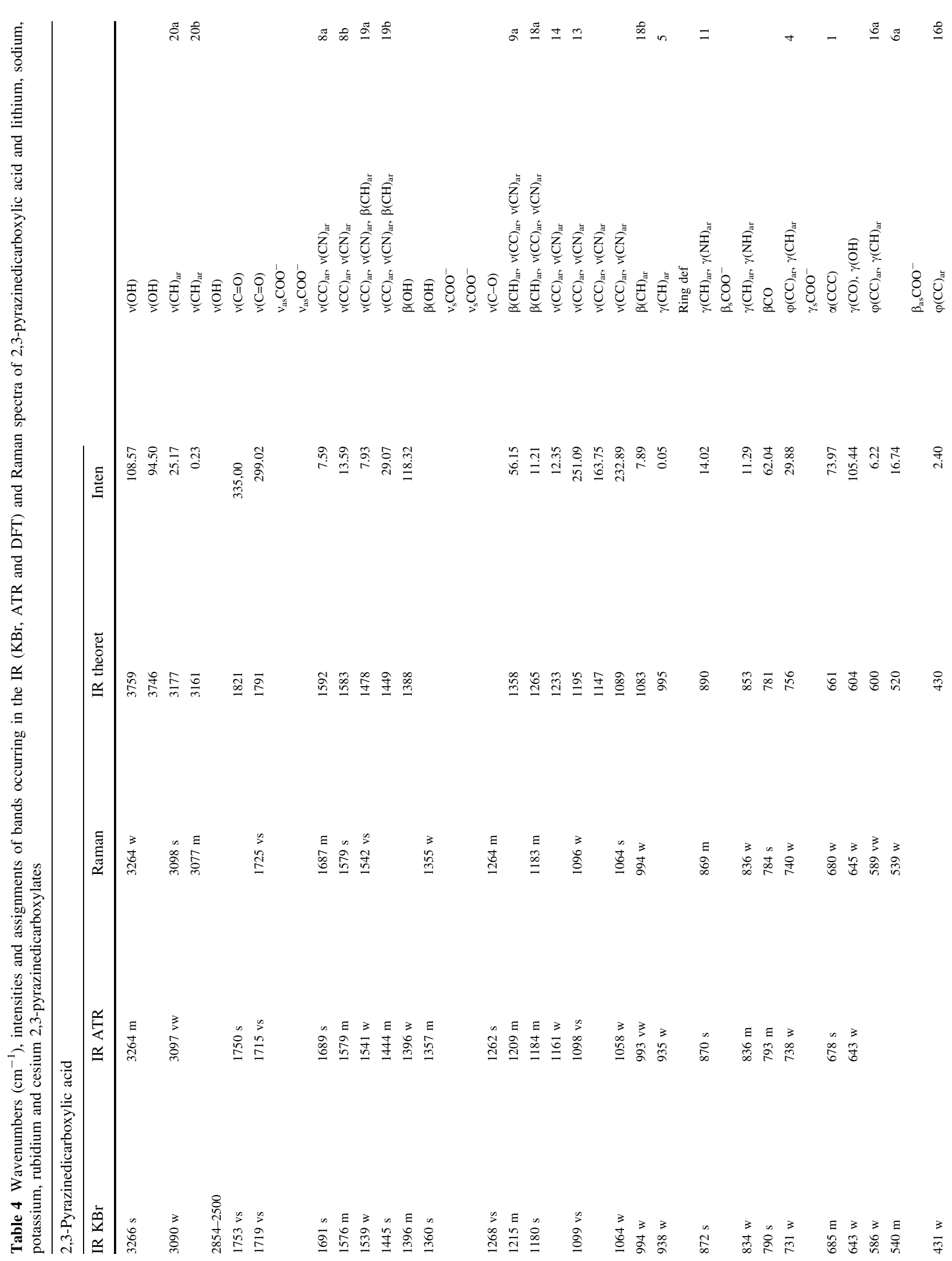




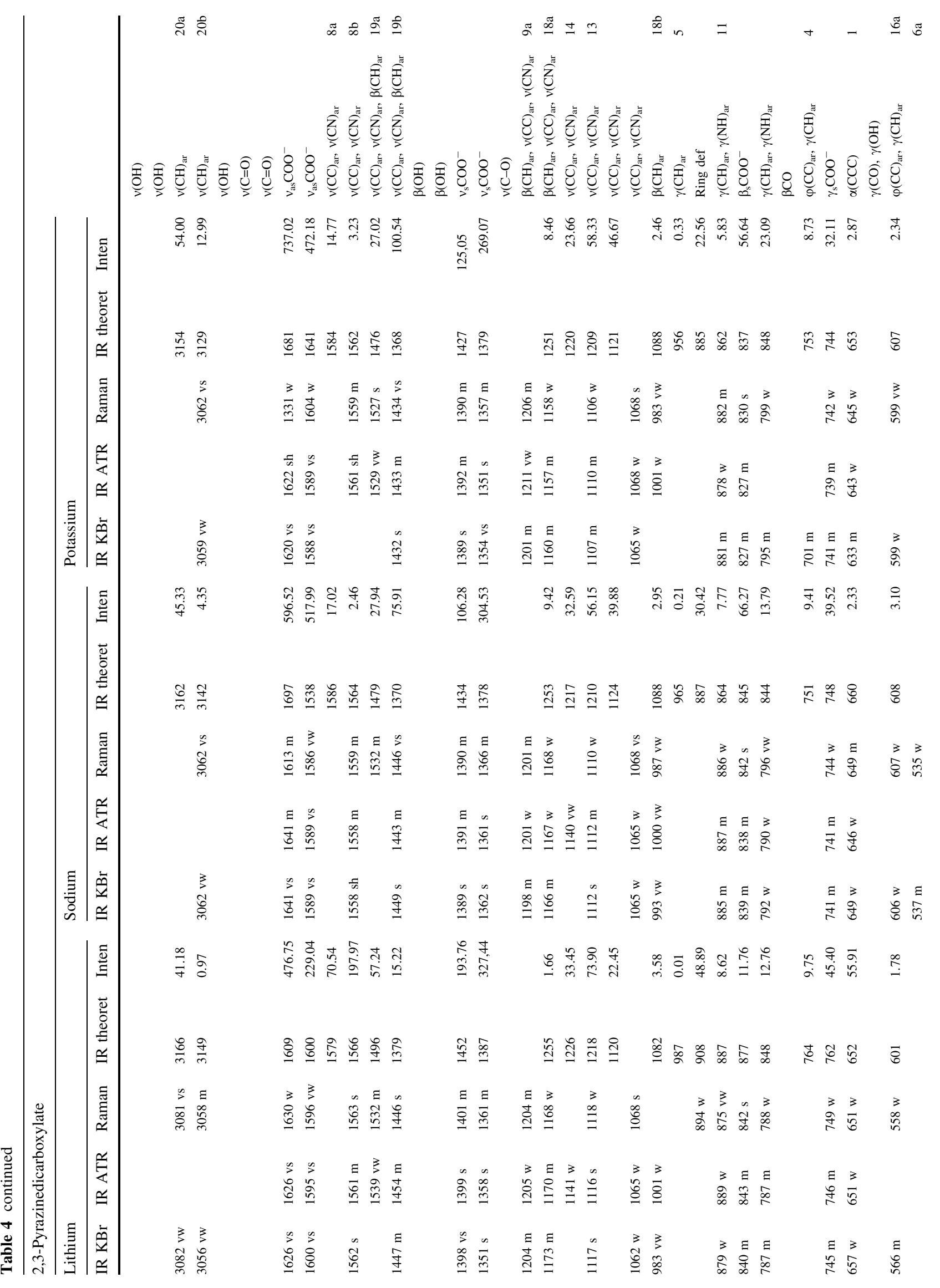




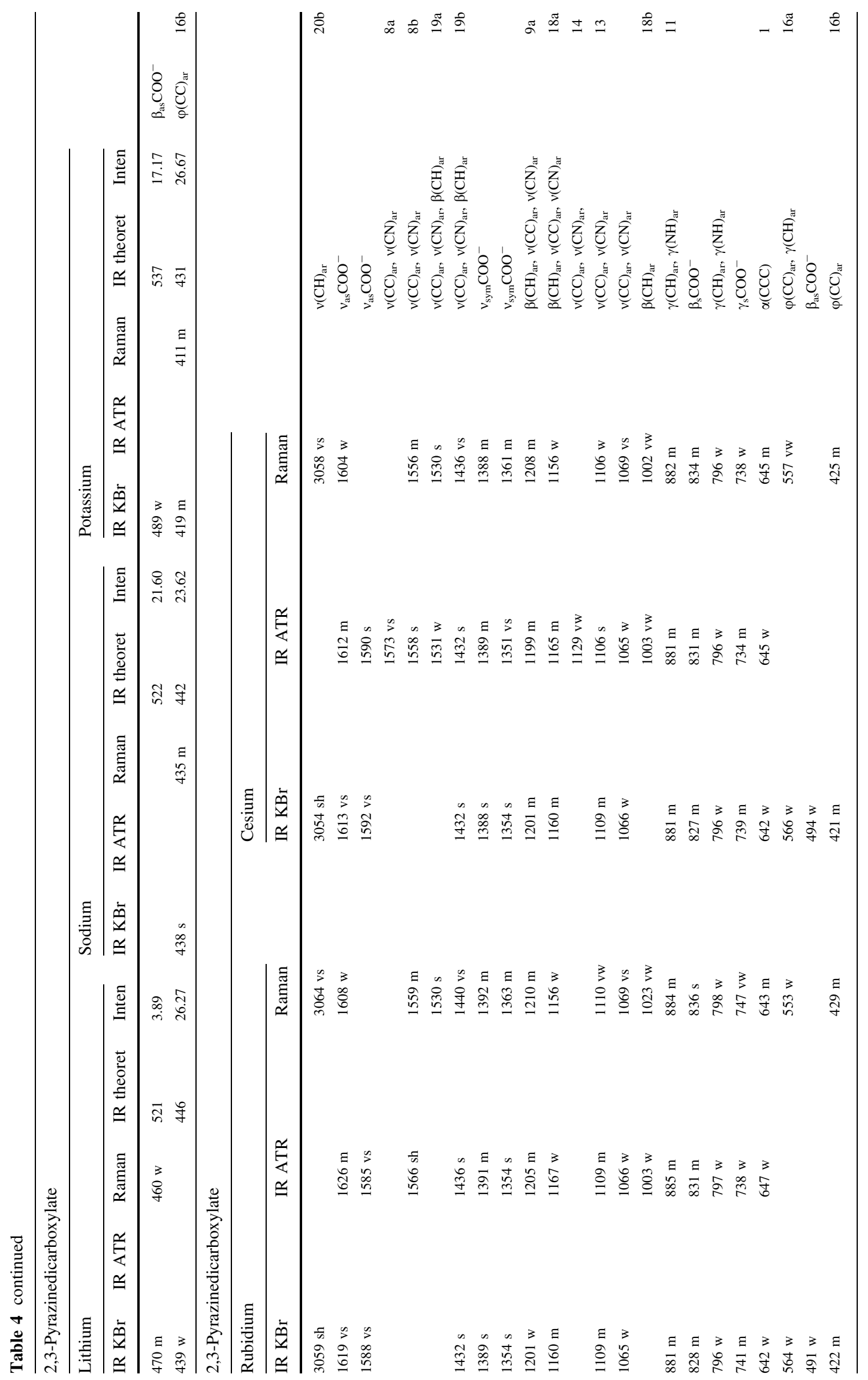




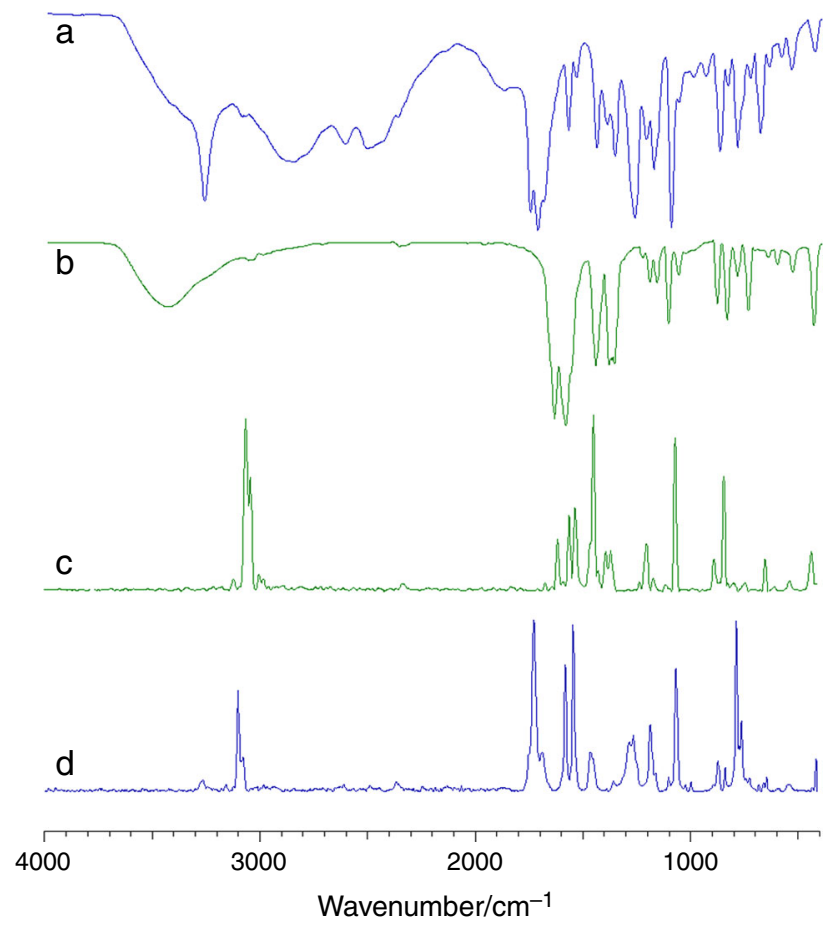

Fig. $3 \operatorname{IR}_{\mathrm{KBr}}(\mathbf{a}, \mathbf{b})$ and Raman (c, d) spectra for 2-pyrazinecarboxylic acid (a, d) and sodium 2-pyrazinecarboxylate $(\mathbf{b}, \mathbf{c})$

intensity of the bands derived from the aromatic system and its shift toward lower wavenumbers in the IR and Raman spectra of the salts, compared to the spectrum of acid result from the decreased force constants and polarization of $\mathrm{C}-\mathrm{H}$ and $\mathrm{C}-\mathrm{C}$ chemical bonds in the ring. This is related to the perturbation of the electron charge distribution in the aromatic ring of the ligand upon the interaction of the alkali metal with the carboxyl group. From our previous works $[57,59,60]$, it follows that the alkali metals disturb the electron system of the aromatic ring in a number of ligands, e.g., benzoic, salicylic and pyridinecarboxylic acids, as well as acids containing five-membered heterocyclic rings.

In the $\mathrm{IR}_{\mathrm{KBr}}, \mathrm{IR}_{\mathrm{ATR}}$ and Raman spectra of 2-pyrazinecarboxylates, as compared with the acid, one observes a disappearance of the band $7 b$ associated with the vibration of the $\mathrm{CH}$ groups of the aromatic ring. The wavenumbers of several bands in the spectra of the salt decrease. These are the bands numbered: $20 \mathrm{~b}, 8 \mathrm{a}, 8 \mathrm{~b}, 19 \mathrm{a}$, 19b, 18b, 6b, 16b (in the $\mathrm{IR}_{\mathrm{KBr}}$ spectra), 20b, 8b, 19b, 5, 11, 6a, 6b (in the $\mathrm{IR}_{\mathrm{ATR}}$ spectra) and 20a, 8a 8b, 19b, 11, 6b, $16 \mathrm{~b}$ (in the Raman spectra). It was also observed that the wavenumbers of some bands derived from the vibration of the aromatic ring increase in the salts, compared to the spectrum of the ligand. These bands are: 20a, 9a, 14, 13, 18a (in the $\operatorname{IR}_{\mathrm{KBr}}$ spectra), 20a, 13, 18a (in the $\mathrm{IR}_{\mathrm{ATR}}$ spectra) and 14, 18a (in the Raman spectra). The $\mathrm{IR}_{\mathrm{KBr}}$,

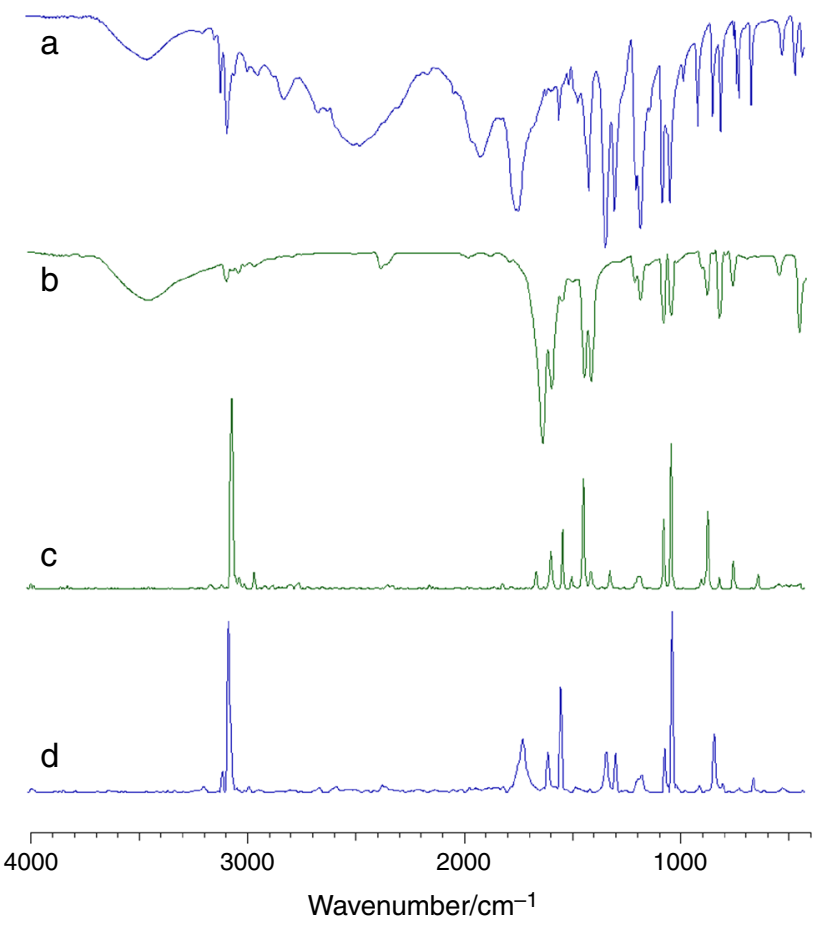

Fig. $4 \operatorname{IR}_{\mathrm{KBr}}(\mathbf{a}, \mathbf{b})$ and Raman (c, d) spectra for 2,3-pyrazinedicarboxylic acid (a, d) and sodium 2,3-pyrazinedicarboxylate $(\mathbf{b}, \mathbf{c})$

$\mathrm{IR}_{\mathrm{ATR}}$ and Raman spectra of the salts there occurred a deformation vibration band of the aromatic ring (labeled 4), which was absent in the spectrum of the acid. In the Raman spectra of the salts appeared bands marked with numbers $19 \mathrm{a}$ and $6 \mathrm{a}$, which were not observed in the spectrum of the acid.

In the studied series of the alkali metal salts of 2-pyrazinecarboxylate, wavenumbers of many aromatic ring bands decrease regularly in the order $\mathrm{Li}-\mathrm{Na}-\mathrm{K}-\mathrm{Rb}-$ Cs. These include the bands $8 \mathrm{a}, 8 \mathrm{~b}, 19 \mathrm{a}, 19 \mathrm{~b}, 9 \mathrm{a}, 18 \mathrm{a}$ (in the $\mathrm{IR}_{\mathrm{KBr}}$ and $\mathrm{IR}_{\mathrm{ATR}}$ spectra) and $8 \mathrm{a}, 19 \mathrm{~b}, 18 \mathrm{a}$ (in the Raman spectra). Based on the analysis of changes in the wavenumber ranges of an aromatic ring of 2-pyrazinecarboxylate, and salts thereof it can be concluded that alkali metals disturb the electronic system of the acid, and that the degree of perturbation increases in the studied series in the order $\mathrm{Li}-\mathrm{Na}-\mathrm{K}-\mathrm{Rb}-\mathrm{Cs}$.

As compared to the free acid, in the spectra of the salt of 2,3-pyrazinedicarboxylate multiple bands derived from the vibration of the aromatic ring disappeared. These bands are indicated by numbers: 20a, 8a, 8b, 19a, 6a, 18b, 5, 4 (in the $\mathrm{IR}_{\mathrm{KBr}}$ spectra), 20a, 8a, 5, 4 (in the $\mathrm{IR}_{\mathrm{ATR}}$ spectra) and 20a, 8a, 4, 6 (in the Raman spectra). Observed was a decrease in the wavenumbers of an aromatic ring vibration. These bands are indicated by numbers: 9a, 18a, 1 (in the $\mathrm{IR}_{\mathrm{KBr}}$ spectra), 8b, 19a, 9a, 18a, 14, 1 (in the $\mathrm{IR}_{\mathrm{ATR}}$ spectra) and 20b, 8b, 19a, 18a, one (in the Raman spectra). 
Wavenumber of some vibrations of the aromatic ring increased in salts with respect to the ligand (lane 13 and 11 present in the $\mathrm{IR}_{\mathrm{KBr}}, \mathrm{IR}_{\mathrm{ATR}}$ and Raman spectra).

Changes in the aromatic ring vibration wavenumbers in the studied series of 2,3PDCA acid salts occur irregularly in the direction Li-Cs. In general, in instances of salts with monocarboxylic acids, these changes are regular in the series Li-Na-K-Rb-Cs (for example: 2-pyrazinecarboxylate [this work], 2-pyridinecarboxylates [48], 3-pyridinecarboxylates and 4-pyridinecarboxylates [47]. Based on changes in wavenumber and intensity of the aromatic ring vibration bands in the salts as compared to the ligand, it can be concluded that alkali metals disturb the electron charge distribution in the aromatic ring of 2,3pyrazinedicarboxylic acid. The effect of alkali metals on the electron charge distribution (decrease in the charge distribution) in the pyrazine ring is much greater in the case of a dicarboxylic acid salt (2PCA) than for the monecarboxylate acid (2,3PDCA).

\section{NMR study}

Chemical shifts of the proton signals in ${ }^{1} \mathrm{H}$ NMR spectra of alkali metal 2-pyrazinecarboxylates (H2: 8.90-9.01, H3: 8.45-8.62, H4: 8.29-8.54) display lower values than those for acids (values: H2: 9.19, H3: 8.84, H4: 8.79) (Table 5). Pyrazine aromatic ring system is disturbed due to the changes in the electron density around the protons of the aromatic ring upon substituting the alkali metal atom to the carboxyl group of the acid. Chemical shift values decrease toward $\mathrm{Li}-\mathrm{Na}-\mathrm{K}-\mathrm{Rb}$. In the case of cesium salt, the mentioned values are similar to those of the sodium salt. A ${ }^{1} \mathrm{H}$ NMR spectrum was registered for 2,3-pyrazinedicarboxylate and its lithium salt. The spectra of the other salts of 2,3-pyrazinedicarboxylate were not registered, due to the very poor solubility of these salts in the available solvents. A comparison of the spectra of 2,3-pyrazinedicarboxylate and its lithium salt implies that lithium disturbs the aromatic ring charge distribution (Table 6). Proton

Table 5 Values of the chemical shifts [ppm] in the spectra of ${ }^{1} \mathrm{H}$ and ${ }^{13} \mathrm{C}$ NMR of 2-pyrazinecarboxylic acid (2-PCA) and its salts determined experimentally and by a theoretical GIAO/B3LYP/6-311++G** method

\begin{tabular}{|c|c|c|c|c|c|c|}
\hline & \multirow[t]{2}{*}{ 2PCA } & \multicolumn{5}{|c|}{ 2-Pyrazinecarboxylate } \\
\hline & & Lithium & Sodium & Potassium & Rubidium & Cesium \\
\hline \multicolumn{7}{|l|}{${ }^{1} \mathrm{HNMR}$} \\
\hline \multicolumn{7}{|l|}{$\mathrm{H} 2$} \\
\hline Exp. & 9.19 & 9.08 & 8.94 & 8.90 & 8.91 & 8.95 \\
\hline Theoret. & 8.69 & 9.74 & 9.73 & 9.71 & - & - \\
\hline \multicolumn{7}{|l|}{$\mathrm{H} 3$} \\
\hline Exp. & 8.84 & 8.62 & 8.48 & 8.45 & 8.47 & 8.50 \\
\hline Theoret. & 8.71 & 8.75 & 8.68 & 8.63 & - & - \\
\hline \multicolumn{7}{|l|}{$\mathrm{H} 4$} \\
\hline Exp. & 8.79 & 8.54 & 8.29 & 8.41 & 8.43 & 8.47 \\
\hline Theoret. & 8.83 & 8.67 & 8.57 & 8.52 & - & - \\
\hline \multicolumn{7}{|l|}{${ }^{13} \mathrm{CNMR}$} \\
\hline \multicolumn{7}{|l|}{$\mathrm{C} 1$} \\
\hline Exp. & 143.89 & 142.75 & 143.12 & 142.99 & 142.88 & 143.15 \\
\hline Theoret. & 164.99 & 151.98 & 153.86 & 154.95 & - & - \\
\hline \multicolumn{7}{|l|}{$\mathrm{C} 2$} \\
\hline Exp. & 145.52 & 145.18 & 144.94 & 144.85 & 144.84 & 144.96 \\
\hline Theoret. & 171.40 & 153.54 & 153.76 & 153.41 & - & - \\
\hline \multicolumn{7}{|l|}{$\mathrm{C} 3$} \\
\hline Exp. & 144.58 & 144.77 & 143.36 & 143.07 & 143.02 & 143.36 \\
\hline Theoret. & 170.61 & 151.41 & 150.33 & 149.57 & - & - \\
\hline \multicolumn{7}{|l|}{$\mathrm{C} 4$} \\
\hline Exp. & 147.68 & 151.05 & 153.37 & 153.97 & 154.12 & 153.23 \\
\hline Theoret. & 165.89 & 148.87 & 148.63 & 148.24 & - & - \\
\hline \multicolumn{7}{|l|}{ C5 } \\
\hline Exp. & 165.09 & 166.16 & 166.29 & 166.14 & 166.13 & 166.25 \\
\hline Theoret. & 187.90 & 186.16 & 179.96 & 179.67 & - & - \\
\hline
\end{tabular}


Table 6 Values of the chemical shifts [ppm] in the spectra of ${ }^{1} \mathrm{H}$ and ${ }^{13} \mathrm{C}$ NMR of 2-pyrazinedicarboxylic acid (2,3PDCA) and its salts determined experimentally and by a theoretical GIAO/B3LYP/6$311++\mathrm{G}^{* *}$ method

\begin{tabular}{|c|c|c|c|c|}
\hline & \multirow[t]{2}{*}{ 2,3PDCA } & \multicolumn{3}{|c|}{ 2,3-Pyrazinedicarboxylate } \\
\hline & & Lithium & Sodium & Potassium \\
\hline \multicolumn{5}{|l|}{${ }^{1} \mathrm{HNMR}$} \\
\hline \multicolumn{5}{|l|}{$\mathrm{H} 3$} \\
\hline Exp. & 8.85 & 8.27 & - & - \\
\hline Theoret. & 8.73 & 8.58 & 8.60 & 8.57 \\
\hline \multicolumn{5}{|l|}{ H4 } \\
\hline Exp. & 8.85 & 8.27 & & \\
\hline Theoret. & 8.78 & 8.61 & 7.69 & 7.73 \\
\hline \multicolumn{5}{|l|}{${ }^{13} \mathrm{CNMR}$} \\
\hline \multicolumn{5}{|l|}{$\mathrm{C} 1$} \\
\hline Exp. & 145.23 & 140.95 & - & - \\
\hline Theoret. & 144.42 & 165.91 & 151.56 & 154.06 \\
\hline \multicolumn{5}{|l|}{$\mathrm{C} 2$} \\
\hline Exp. & 145.23 & 140.95 & - & - \\
\hline Theoret. & 158.43 & 144.82 & 169.53 & 169.99 \\
\hline \multicolumn{5}{|l|}{$\mathrm{C} 3$} \\
\hline Exp. & 145.59 & 151.42 & - & - \\
\hline Theoret. & 158.87 & 145.28 & 151.17 & 150.37 \\
\hline \multicolumn{5}{|l|}{$\mathrm{C} 4$} \\
\hline Exp. & 145.59 & 151.42 & - & - \\
\hline Theoret. & 148.36 & 151.05 & 139.28 & 138.18 \\
\hline \multicolumn{5}{|l|}{$\mathrm{C} 5$} \\
\hline Exp. & 165.97 & 169.70 & - & - \\
\hline Theoret. & 169.86 & 182.66 & 169.61 & 171.51 \\
\hline \multicolumn{5}{|l|}{ C6 } \\
\hline Exp. & 165.97 & 169.70 & - & - \\
\hline Theoret. & 170.42 & 187.43 & 179.91 & 178.70 \\
\hline
\end{tabular}

chemical shift values (in experimental 1HNMR spectra for lithium 2,3-pyrazinedicarboxylate: $\mathrm{H} 3, \mathrm{H} 4:$ 8.85) are lower in salt than in acid (H3, H4: 8.27). Theoretical calculations show that in the case of sodium and potassium salts chemical shift values are also lower than the corresponding chemical shifts for protons in the ligand. It is therefore concluded that the alkali metals disturb the electron system of the aromatic ring of 2,3-pyrazinedicarboxylate. Effect of alkali metals on the electronic charge distribution is higher in the case of 2,3-pyrazinecarboxylate. Changes in the chemical shifts of protons in the salts of a ligand are greater for 2,3-pyrazinedicarboxylates than 2-pyrazinecarboxylates. This is evidenced both by chemical shift values that were determined experimentally and those theoretically calculated.

After substituting the alkali metal atom in the carboxyl group of 2-pyrazinecarboxylate a slight increase can be seen in chemical shifts of carbon of the carboxyl group in
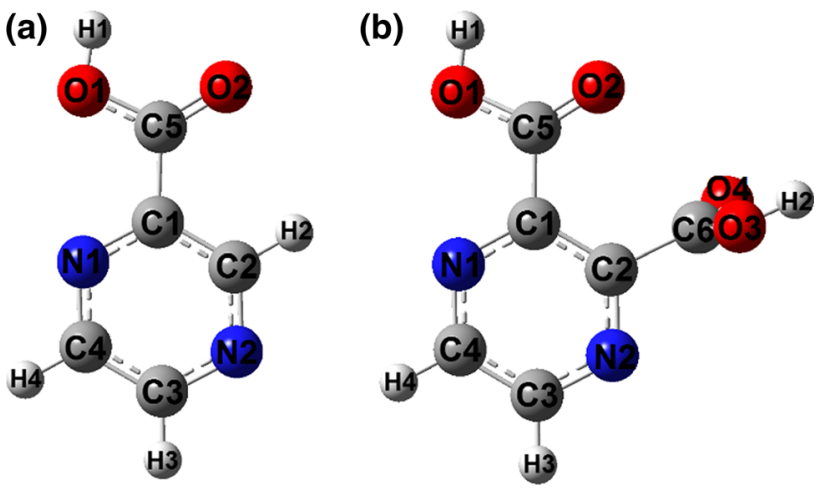

Fig. 5 Numbering of the atoms in the 2-pyrazinecarboxylic acid (a) and 2,3-pyrazinedicarboxylic acid (b)

the ${ }^{13} \mathrm{C}$ NMR spectra due to the decrease in the electron density around the carbon atom of the carboxyl group. Much more pronounced changes were observed in the chemical shifts of atoms of an aromatic ring. In the 2-pyrazinecarboxylates, the electron density on the carbon atoms numbered $\mathrm{C} 1, \mathrm{C} 2$, and $\mathrm{C} 3$ (Fig. 5a) increases in relation to that of the ligand, what is observed as a decrease in the chemical shifts in the spectra of ${ }^{13} \mathrm{C}$-NMR. The electron density at the $\mathrm{C} 4$ atom decreases-an increase is observed in ${ }^{13} \mathrm{C}$ chemical shift values in the salts in relation to the acid. Changes in chemical shifts of carbons for 2-pyrazinecarboxylates of alkali metals with respect to 2-pyrazinecarboxylic acid indicate that alkali metals disturb the electron charge distribution in the aromatic ring of the ligand. An increase in the perturbation of the electron charge distribution was observed along the series $\mathrm{Li}-\mathrm{Na}-$ $\mathrm{K}-\mathrm{Rb}$. A comparison of the chemical shifts in the spectra of ${ }^{13} \mathrm{C}$-NMR implies that the effect of cesium on the electron charge distribution of 2-pyrazinecarboxylic acid is similar to that of sodium (similar chemical shifts in the salts of sodium and cesium), which was confirmed by the proton spectra of the studied compounds.

Significant changes in the chemical shifts of carbons in the ${ }^{13} \mathrm{C}$ NMR spectrum were observed in the case of lithium substitution to the carboxyl groups of 2,3pyrazinedicarboxylate. The values of the chemical shifts of atoms indicated $\mathrm{C} 1$ and $\mathrm{C} 2$ (Fig. 5b) decrease (indicating an increase in the electron density) and the remaining atoms of the aromatic ring increase (decrease in electron density). Changes in chemical shifts of carbons in the NMR spectra of the salt with respect to the ligand calculated theoretically are greater for alkali metal 2,3-pyrazinedicarboxylates than for 2-pyrazinecarboxylates.

\section{Aromaticity and NBO analysis}

Upon the substitution of the alkali metal atom to the carboxylic group of 2-pyrazinecarboxylic, and 2,3- 
Table 7 Aromaticity indices (HOMA, GEO, EN) and Bird's index ( $\left.I_{6}\right)$ for 2PCA, 2,3PDCA and their salts (lithium, sodium, potassium) (calculated for the structure optimized in B3LYP/6-311++G**)

\begin{tabular}{|c|c|c|c|c|c|c|c|c|}
\hline \multirow[t]{2}{*}{ Aromaticity indices } & \multirow[t]{2}{*}{ 2PCA } & \multicolumn{3}{|c|}{ 2-Pyrazinecarboxylate } & \multirow[t]{2}{*}{ 2,3PDCA } & \multicolumn{3}{|c|}{ 2,3-Pyrazinedicarboxylate } \\
\hline & & $\mathrm{Li}$ & $\mathrm{Na}$ & $\mathrm{K}$ & & $\mathrm{Li}$ & $\mathrm{Na}$ & $\mathrm{K}$ \\
\hline HOMA & 0.991 & 0.988 & 0.990 & 0.989 & 0.985 & 0.969 & 0.952 & 0.952 \\
\hline $\mathrm{EN}$ & 0.003 & 0.005 & 0.004 & 0.004 & 0.003 & 0.007 & 0.010 & 0.015 \\
\hline GEO & 0.006 & 0.007 & 0.006 & 0.007 & 0.013 & 0.024 & 0.039 & 0.033 \\
\hline$I_{6}$ & 89.44 & 89.59 & 88.76 & 88.62 & 90.31 & 90.11 & 86.85 & 84.95 \\
\hline
\end{tabular}

(a)

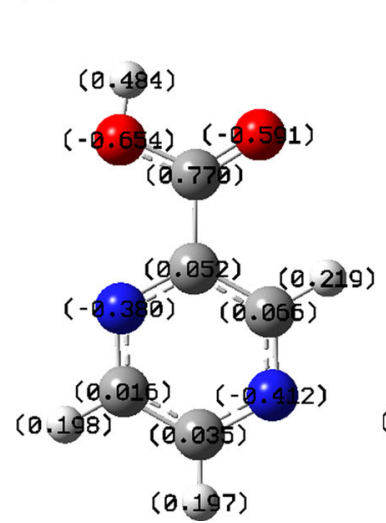

(b)
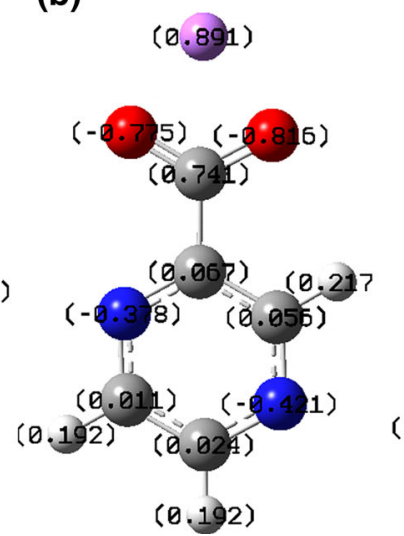

(c)
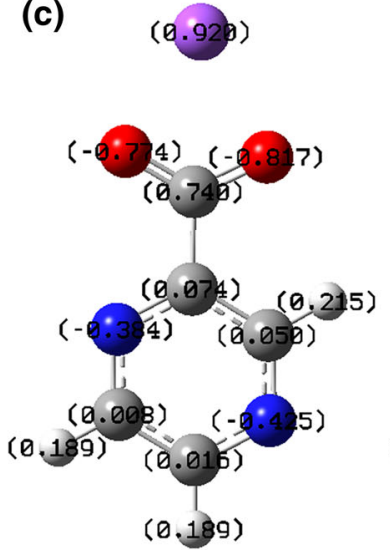

(d)

(0) (0.94)

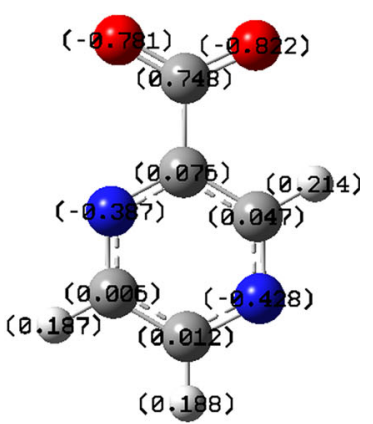

Fig. 6 Electron charge distribution calculated by NBO in B3LYP/6-311++G** for 2-pyrazinecarboxylic (a) acid and lithium (b), sodium (c) and potassium (d) 2-pyrazinecarboxylates

(a)

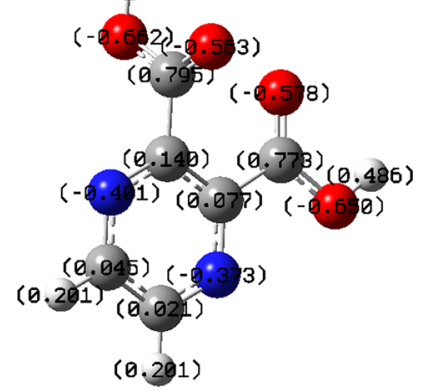

(b)

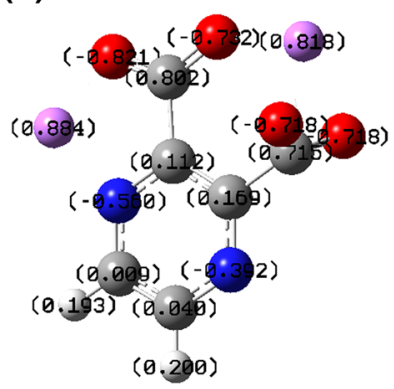

(c)

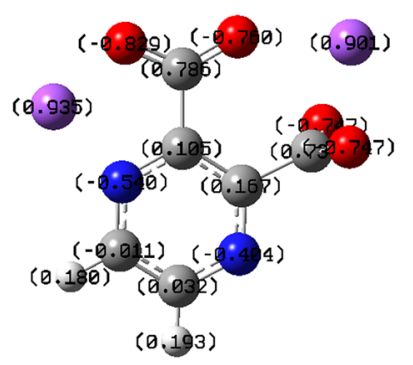

(d)

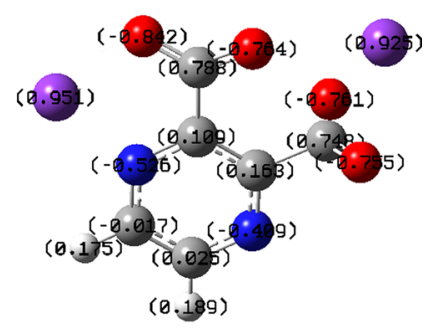

Fig. 7 Electron charge distribution calculated by NBO in B3LYP/6-311++G** for 2,3-pyrazinedicarboxylic acid (a) and lithium (b), sodium (c) and potassium (d) 2,3-pyrazinedicarboxylates

pyrazinedicarboxylic acids, the aromaticity of the pyrazine ring decreased. Calculated HOMA aromaticity indices and Bird's $I_{6}$ indices display the lower values for the salt in comparison with the ligands (Table 7). Comparing the ligand of Table 7, we found that alkali metals have much greater impact on the aromaticity change (decrease in the aromaticity index values) of 2,3-pyrazinedicarboxylic acid than of the 2-pyrazinecarboxylic acid.

The values of the electronic charges in ligands (2PCA and 2,3PDCA) and their salts of lithium, sodium and potassium were calculated using NBO (natural bond orbital method). Upon the substitution of the alkali metal atom in the carboxyl group of 2PCA, a change in the charge distribution of electron on the carbon of the carboxyl group and the aromatic ring occurred (Fig. 6). An increase in the value of the electron charge with respect to the carboxylic acid group occurred on the oxygen atoms in the carboxylate anion of salts. A small increase in the value of electron charge was calculated by NBO (B3LYP/6-311++G**), for the nitrogen atoms in the pyrazine ring of $2 \mathrm{PCA}$ salts with 
respect to that of the ligand. The electronic charge on the carbon atoms No C2, C3 and C4 increases, while it decreases on the $\mathrm{C} 1$ atom. The changes in the charge values occur along the $2 \mathrm{PCA}-\mathrm{Li}-\mathrm{Na}-\mathrm{K}$ series. The electronic charge on aromatic protons of lithium, sodium and potassium 2-pyrazinecarboxylates increases as compared with the ligand. Similar changes were observed in the experimental ${ }^{1} \mathrm{H}-\mathrm{NMR}$ spectra-chemical shifts were reduced in a series $2 \mathrm{PCA}-\mathrm{Li}-\mathrm{Na}-\mathrm{K}-\mathrm{Rb}-\mathrm{Cs}$, which implies the increasing values of electron density on the aromatic protons.

The electronic charge on nitrogen atoms in the pyrazine ring in lithium, sodium and potassium 2,3-pyrazinedicarboxylate increases significantly with respect to the ligand (Fig. 7). The values of electronic charge on the aromatic ring carbons of the 2,3PDCA salts also vary from the value for the ligand. These changes in the alkali metal 2,3pyrazinedicarboxylates are greater than in the 2-pyrazinecarboxylates.

\section{Conclusions}

On the basis of experimental and theoretical calculations, it was found that:

1. Comparing the curves of the thermal decomposition of the alkali metal salt of studied acids one can conclude that salts of 2-pyrazinecarboxylic acid have a higher thermal stability than the salts of 2,3pyrazinedicarboxylate.

2. Spectroscopic (IR, Raman and NMR) data showed that alkali metals disturb the electronic system of the aromatic ring of ligands, (of 2-pyrazinecarboxylate, and 2,3-pyrazinedicarboxylate). The degree of perturbation increases in the studied series salts in order: $\mathrm{Li}-$ $\mathrm{Na}-\mathrm{K}-\mathrm{Rb}-\mathrm{Cs}$.

3. Experimental studies showed that alkali metals to much greater extent impact on the electronic charge distribution of 2,3-pyrazinedikarboxylic than of 2-pyrazinecarboxylic acid.

4. Theoretical calculations (aromaticity index values, the charge distribution by NBO) performed for geometrically optimized structures confirm the results of experiments on the effect of alkali metals on the electron charge distribution of ligand.

Acknowledgements This work was supported by Bialystok University of Technology in the frame of funding for statutory research (No. S/WBiIŚ/1/2012). Thermogravimetric research was performed at the Center of Synthesis and Analysis BioNanoTechno of the University of Bialystok. The equipment in the Center of Synthesis and Analysis BioNanoTechno of University of Bialystok was funded by the EU, Project: POPW.01.03.00-20-034/09-00.
Open Access This article is distributed under the terms of the Creative Commons Attribution 4.0 International License (http://crea tivecommons.org/licenses/by/4.0/), which permits unrestricted use, distribution, and reproduction in any medium, provided you give appropriate credit to the original author(s) and the source, provide a link to the Creative Commons license, and indicate if changes were made.

\section{References}

1. Müller R, Rappert S. Pyrazines: occurrence, formation and biodegradation. Appl Microbiol Biotechnol. 2010;85:1315-20.

2. Wagner R, Czerny M, Bielohradsky J, Grosch W. Structureodour-activity relationships of alkylpyrazines. Z Für Leb Forsch A. 1999;208:308-16.

3. Hogben CAM, Tocco DJ, Brodie BB, Schanker LS. On the mechanism of intestinal absorption of drugs. J Pharmacol Exp Ther. 1959;125:275-82.

4. Jakoby WB. Metabolic basis of detoxication. Elsevier; 2012.

5. Schanker LS, Shore PA, Brodie BB, Hogben CAM. Absorption of drugs from the stomach I. The rat. J Pharmacol Exp Ther. 1957;120:528-39.

6. Sausville JW, Spoerri PE. Syntheses in the Pyrazine Series. IV. 2-Sulfanilamidopyrazine. J Am Chem Soc. 1941;63:3153-4.

7. Ambrogi V, Bloch K, Daturi S, Logemann W, Parenti M. Synthesis of pyrazine derivatives as potential hypoglycemic agents. J Pharm Sci. 1972;61:1483-6.

8. Khamar BM, Singh C, Modi RI. Hypoglycemic compounds. U.S. Patent No 9,029,56. 2015.

9. Meurer LC, Tolman RL, Chapin EW, Saperstein R, Vicario PP, Zrada MM, et al. Synthesis and hypoglycemic activity of substituted 8-(1-piperazinyl) imidazo [1, 2-a] pyrazines. J Med Chem. 1992;35:3845-57.

10. Yuan K, Ma S, Zhu L, Liu H. Salts of methyl (R)-7-[3-amino-4(2, 4, 5-trifluoro-phenyl)-butyryl]-3-trifluoromethyl-5, 6, 7, 8-tetrahydro-imidazo [1, 5-A] pyrazine-1-carboxylate. 2013.

11. Bicking JB, Mason JW, Woltersdorf OW Jr, Jones JH, Kwong SF, Robb CM, et al. Pyrazine diuretics. I. N-amidino-3-amino-6halopyrazinecarboxamides. J Med Chem. 1965;8:638-42.

12. Dolezal M, Zitko J. Pyrazine derivatives: a patent review (June 2012-present). Expert Opin Ther Pat. 2015;25:33-47.

13. Ukrainets I, Bereznyakova N. Heterocyclic diuretics. Chem Heterocycl Compd. 2012;48:1-11.

14. Krátký M, Vinšová J, Novotná E, Stolaříková J. Salicylanilide pyrazinoates inhibit in vitro multidrug-resistant Mycobacterium tuberculosis strains, atypical mycobacteria and isocitrate lyase. Eur J Pharm Sci. 2014;53:1-9.

15. Kushner S, Dalalian H, Sanjurjo J, Bach F Jr, Safir S, Smith V Jr, et al. Experimental chemotherapy of tuberculosis. II. The synthesis of pyrazinamides and related compounds1. J Am Chem Soc. 1952;74:3617-21.

16. Foks H, Balewski L, Gobis K, Dabrowska-Szponar M, Wisniewska K. Studies on pyrazine derivatives LII: antibacterial and antifungal activity of nitrogen heterocyclic compounds obtained by pyrazinamidrazone usage. Heteroat Chem. 2012;23:49-58.

17. Lima CHS, Henriques GMO, Candea LPA, Lourenco CSM, Bezerra AFMF, Ferreira LM, Kaiser RC, de Souza VNM. Synthesis and Antimycobacterial Evaluation of $\mathrm{N}^{\prime}-(\mathrm{E})$-heteroaromaticpyrazine-2-carbohydrazide derivatives. Med Chem. 2011;7:245-9.

18. Judge V, Narasimhan B, Ahuja M. A review of biological potential of pyrazinamide derivatives. Hygeia J Drugs Med. 2012;4:1-6. 
19. de L. Ferreira M, Candea Andre LP, de O H, Maria das Gracas M, Kaiser CR, da S LCH, de Souza MVN. Synthesis and cytotoxic evaluation of disubstituted n-acylhydrazones pyrazinecarbohydrazide derivatives. Lett Drug Des Discov. 2010;7:275-80.

20. Vergara FM, Lima CH da S, Maria das Graças M de O, Candéa AL, Lourenço MC, Ferreira M de L, Kaiser RC, de Souza VNM. Synthesis and antimycobacterial activity of $\mathrm{N}^{\prime}$-[(E)-(monosubstituted-benzylidene)]-2-pyrazinecarbohydrazide derivatives. Eur J Med Chem 2009;44:4954-9.

21. Sigroha S, Narasimhan B, Kumar P, Khatkar A, Ramasamy K, Mani V, et al. Design, synthesis, antimicrobial, anticancer evaluation, and QSAR studies of 4-(substituted benzylidene-amino)1, 5-dimethyl-2-phenyl-1, 2-dihydropyrazol-3-ones. Med Chem Res. 2012;21:3863-75.

22. Aly AA, Nour-El-Din AM. Functionality of amidines and amidrazones. Arkivoc. 2008;1:153-94.

23. Srivastava K, Purohit S, Singhal S. Studies on nitrogen and sulphur containing heterocyclic compound: 1, 3, 4-thiadiazole. Asian J Biomed Pharm Sci 2013; 3:6.

24. Zhang Z, Wei T, Hou J, Li G, Yu S, Xin W. Tetramethylpyrazine scavenges superoxide anion and decreases nitric oxide production in human polymorphonuclear leukocytes. Life Sci. 2003;72:2465-72.

25. Feng L, Ke N, Cheng F, Guo Y, Li S, Li Q, et al. The protective mechanism of ligustrazine against renal ischemia/reperfusion injury. J Surg Res. 2011;166:298-305.

26. Liu S, Cai Y, Evans TW, McCormack DG, Barer GR, Barnes PJ. Ligustrazine is a vasodilator of human pulmonary and bronchial arteries. Eur J Pharmacol. 1990;191:345-50.

27. Sun L, Li Y, Shi J, Wang X, Wang X. Protective effects of ligustrazine on ischemia-reperfusion injury in rat kidneys. Microsurgery. 2002;22:343-6.

28. Chen L, Lu Y, Wu J, Xu B, Zhang L, Gao M, et al. Ligustrazine inhibits B16F10 melanoma metastasis and suppresses angiogenesis induced by vascular endothelial growth factor. Biochem Biophys Res Commun. 2009;386:374-9.

29. Jiang F, Qian J, Chen S, Zhang W, Liu C. Ligustrazine improves atherosclerosis in rat via attenuation of oxidative stress. Pharm Biol. 2011;49:856-63.

30. Peng W, Hucks D, Priest R, Kan Y, Ward J. Ligustrazine-induced endothelium-dependent relaxation in pulmonary arteries via an NO-mediated and exogenous L-arginine-dependent mechanism. Br J Pharmacol. 1996;119:1063-71.

31. Adams A, De Kimpe N. Formation of pyrazines from ascorbic acid and amino acids under dry-roasting conditions. Food Chem. 2009;115:1417-23.

32. Arnoldi A, Arnoldi C, Baldi O, Griffini A. Flavor components in the Maillard reaction of different amino acids with fructose in cocoa butter-water. Qualitative and quantitative analysis of pyrazines. J Agric Food Chem. 1988;36:988-92.

33. Hawksworth G, Scheline RR. Metabolism in the rat of some pyrazine derivatives having flavour importance in foods. Xenobiotica. 1975;5:389-99.

34. Maga JA. Pyrazine update. Food Rev Int. 1992;8:479-558.

35. Ferreira SB, Kaiser CR. Pyrazine derivatives: a patent review (2008 - present). Expert Opin Ther Pat. 2012;22:1033-51.

36. Ura Y, Sakata G, Makino K, Kawamura Y, Ikai T, Oguti T. Quinoxaline derivatives and herbicidal composition. U.S. Patent No. 5,364,831. 1994.

37. Hayes AW. Principles and methods of toxicology [Internet]. [New York]: CRC Press; 2007 [cited 2015 Oct 15]. http://www. crcnetbase.com/isbn/9780849337789.

38. Yumino K, Kawakami I, Tamura M, Hayashi T, Nakamura M. Paraquat-and diquat-induced oxygen radical generation and lipid peroxidation in rat brain microsomes. J Biochem (Tokyo). 2002;131:565-70.
39. Nakamura A, Ataka T, Segawa H, Takeuchi Y, Takematsu T. Structure-activity relationship of herbicidal 2, 3-dicyano-5-substituted pyrazines. Agric Biol Chem. 1983;47:1555-60.

40. Doležal M, Král'ová K. Synthesis and evaluation of pyrazine derivatives with herbicidal activity. INTECH Open Access Publisher; 2011.

41. Jackson G, Einsele H, Moreau P, Miguel JS. Bortezomib, a novel proteasome inhibitor, in the treatment of hematologic malignancies. Cancer Treat Rev. 2005;31:591-602.

42. Richardson PG, Sonneveld P, Schuster MW, Irwin D, Stadtmauer EA, Facon T, et al. Bortezomib or high-dose dexamethasone for relapsed multiple myeloma. N Engl J Med. 2005;352:2487-98.

43. Kamal A, Ramakrishna G, Raju P, Rao AVS, Viswanath A, Nayak VL, et al. Synthesis and anticancer activity of oxindole derived imidazo[1,5-a]pyrazines. Eur J Med Chem. 2011;46:2427-35.

44. Rodrigues FA, Bomfim I da S, Cavalcanti BC, do Ó Pessoa C, Pinheiro AC, Lima CH, de Souza VNM. Biological evaluation of pyrazinamide derivatives as an anticancer class. Eur Chem Bull. 2014;3:358-61.

45. Lewandowski W, Kalinowska M, Lewandowska H. The influence of metals on the electronic system of biologically important ligands. Spectroscopic study of benzoates, salicylates, nicotinates and isoorotates. Review. J Inorg Biochem. 2005;99:1407-23.

46. Lewandowski W, Fuks L, Kalinowska M, Koczoń P. The influence of selected metals on the electronic system of biologically important ligands. Spectrochim Acta A Mol Biomol Spectrosc. 2003;59:3411-20.

47. Koczoń P, Hrynaszkiewicz T, Świsłocka R, Samsonowicz M, Lewandowski W. Spectroscopic (Raman, FT-IR, and NMR) study of alkaline metal nicotinates and isonicotinates. Vib Spectrosc. 2003;33:215-22.

48. Świderski G, Wojtulewski S, Kalinowska M, Świsłocka R, Lewandowski W. Effect of alkali metal ions on the pyrrole and pyridine $\pi$-electron systems in pyrrole-2-carboxylate and pyridine-2-carboxylate molecules: FT-IR, FT-Raman, NMR and theoretical studies. J Mol Struct. 2011;993:448-58.

49. Doležal M, Zitko J, Jampílek J. Pyrazinecarboxylic acid derivatives with antimycobacterial activity. 2012.

50. Gaussian09 RA. 1, MJ Frisch, GW Trucks, HB Schlegel, GE Scuseria, MA Robb, JR Cheeseman, G. Scalmani, V. Barone, B. Mennucci, GA Petersson, et al., Gaussian. Inc Wallingford CT. 2009.

51. Beaula TJ, Packiavathi A, Manimaran D, Joe IH, Rastogi V, Jothy VB. Quantum chemical computations, vibrational spectroscopic analysis and antimicrobial studies of 2, 3-Pyrazinedicarboxylic acid. Spectrochim Acta A Mol Biomol Spectrosc. 2015;138:723-35.

52. Rode JE, Dobrowolski JC, Jamróz MH, Borowiak MA. Theoretical IR, Raman and NMR spectra of 1, 2-and 1, 3-dimethylenecyclobutane. Vib Spectrosc. 2001;25:133-49.

53. Reed AE, Weinstock RB, Weinhold F. Natural population analysis. J Chem Phys. 1985;83:735-46.

54. Krygowski TM, Cyrański M. Separation of the energetic and geometric contributions to the aromaticity. Part IV. A general model for the $\pi$-electron systems. Tetrahedron. 1996;52:10255-64.

55. Bird C. A new aromaticity index and its application to fivemembered ring heterocycles. Tetrahedron. 1985;41:1409-14.

56. Varsányi G. Vibrational spectra of benzene derivatives. Oxford: Elsevier; 2012.

57. Lewandowski W, Świderski G, Świslocka R, Wojtulewski S, Koczoń P. Spectroscopic (Raman, FT-IR and NMR) and theoretical study of alkali metal picolinates. J Phys Org Chem. 2005; 18:918-28.

58. Świsłocka R, Regulska E, Samsonowicz M, Lewandowski W. Experimental (FT-IR, FT-Raman, $1 \mathrm{H}, 13 \mathrm{C} \mathrm{NMR}$ ) and theoretical study of alkali metal 2-aminonicotinates. Polyhedron. 2009;28:3556-64. 
59. Kalinowska M, Siemieniuk E, Kostro A, Lewandowski W. The application of $\mathrm{A} \mathrm{j}$, BAC, I 6, HOMA indexes for quantitative determination of aromaticity of metal complexes with benzoic, salicylic, nicotinic acids and benzene derivatives. J Mol Struct Theochem. 2006;761:129-41.
60. Kalinowska M, Świsłocka R, Borawska M, Piekut J, Lewandowski W. Spectroscopic (FT-IR, FT-Raman, UV) and microbiological studies of di-substituted benzoates of alkali metals. Spectrochim Acta A Mol Biomol Spectrosc. 2008;70:126-35. 